\title{
The Four Impossibilities in Physics
}

\author{
Dr.(Prof.) V.C.A. NAIR* \\ Educational Physicist, Distinguished Alumnus, Chancellor-Designated Resource Person in the \\ area of Physics and Research Guide for Physics at Shri J.J.T University, Rajasthan-333001, \\ India.
}

*nairvca39@gmail.com

\begin{abstract}
This is an exhaustive research paper prepared by a physicist of long-standing experience of teaching Applied Physics and who have published a large number of Papers in International Journals. The author begins with a Philosophy. The meaning of the title is clearly explained by means of a Chart; Historical aspects of Vacuum starting from Otto Von Guericke, The Torricellian vacuum and the development of the Vacuum Pump; Some elementary Mathematics to show that absolute vacuum cannot be obtained; Guericke's crucial tests for testing vacuum; Geissler's vacuum pump and the development of diffusion pumps,; The Quantum Vacuum; Planck's law of radiation and also Planck's second law of radiation. The Zero Point Energy (ZPE); ZPE from Uncertainty Principle; Energy Levels of Quantum Oscillator; Vacuum Energy = Dark Energy; LHC is referred to as the largest Vacuum ever made; The Casimir Effect; Absolute Zero and the Bose-Einstein Condensate and its discovery; The Nernst Heat Theorem and the Third Law of Thermodynamics; Concept of Negative Temperatures; The paper ends with a Conclusion and the readers are particularly advised to read the Conclusion wherein the author has referred the ZPE, $\frac{1}{2} \mathrm{~h} v$ as a Quantum Magician and the caricature of many scientists running towards the Absolute Zero and failing in their efforts.

The author has touched topics from Aristotle to Einstein with some 22 pictures of scientists given in chronological order of their years of birth. In addition, there are some 20 illustrative diagrams some of which are drawn free hand by author.
\end{abstract}

Keywords: Bose Condensation, Bose-Einstein Condensate, Casimir Effect. Dark Energy, Diffusion Pump, Energy levels of Quantum Oscillator, Geissler Vacuum Pumps, Negative temperatures, Nernst Heat Theorem, Otto Von Guericke's Vacuum, Planck's second law of radiation, Quantum Vacuum, Third Law of Thermodynamics, Torricellian Vacuum, Vacuum fluctuations, Zero-Point Energy (ZPE)

Philosophy*: "All the pictures which Science draws of Nature and which alone seem capable of according with observational fact, are mathematical pictures. . . . . From the intrinsic evidence of His creation, the Great Architect of the Universe now begins to appear as a pure Mathematician." *[25]

\section{INTRODUCTION}

1.1 The Title of the Paper is very interesting. When we talk of an impossibility, as a scientist, the question that arises is, Is it a theoretical impossibility? or Is it a practical Impossibility? We have to deal with the second question because the answer to the first question is a simple mathematical operation leading to calamities such as bringing the Big Bang to Bring Crunch or even toppling the Universe. Before we proceed with the subject matter of the Paper, we shall take up the first Impossibility, i.e obtaining 'Vacuum' and start with some of the historical aspects of obtaining vacuum 
International Advanced Research Journal in Science, Engineering and Technology

Vol. 7, Issue 10, October 2020

DOI 10.17148/IARJSET.2020.71006

1.2 The Meaning of Title in a nut-shell: The entire paper can be represented by a self-explanatory Chart shown in Fig.1. The names of scientists involved in the respective Impossibilities are given at the bottom of each Impossibility. Creating a vacuum which we generally talk of is taken as the first Impossibility and in fact it is the leading member. The Impossibility-II is the Quantum Vacuum which, in fact, is an explanation for failure to obtain absolute vacuum. Quantum Vacuum with proper explanation as mentioned in the theory is the answer for that. Now, the Impossibilities III and IV are common with Modern Physics. That is the Absolute Zero $\left(-273.16^{\circ} \mathrm{C}\right)$. The un-attainability of this temperature is the Impossibility. But, the scientists mentioned have gone very near to that temperature and seen some wonders as we will see in the details in the Paper. We shall begin with the first Impossibility of getting a reasonably high vacuum and start with the historical aspects of the same.

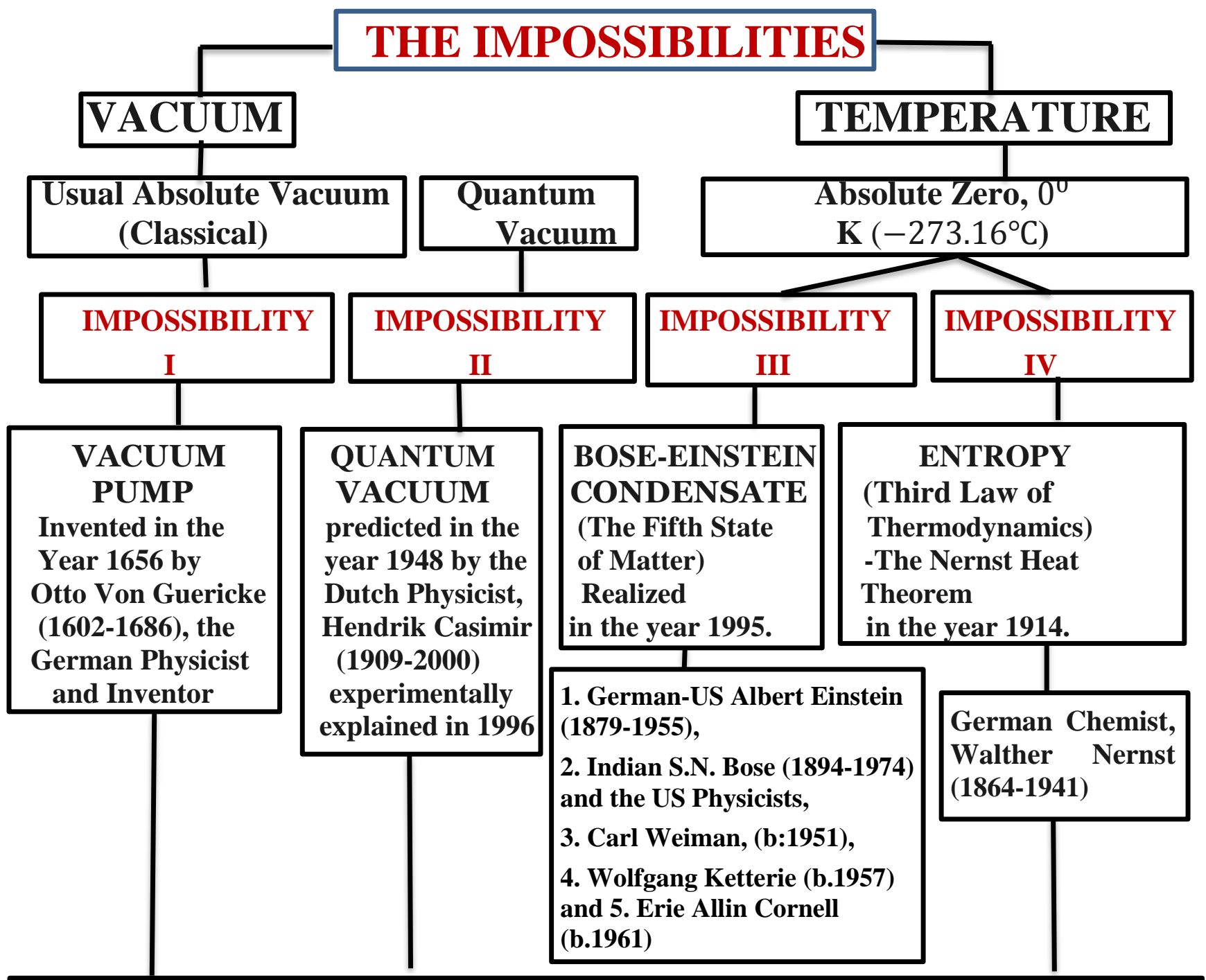

1. Matter and Energy in some form or other exist even in an assumed Absolute Vacuum or at Quantum Vacuum (Casimir Effect).

2. In the $2^{\text {nd }}$ form of Planck's Law stated in 1911-12, Matter and Energy exist even at Absolute Zero, i.e the Zero Point Energy, $\mathrm{E}_{0}=\mathbf{h}\left(\frac{v}{2}\right)$ where $\mathrm{h}$ is the Planck's constant and $v$ the frequency

Fig. 1 A self-explanatory Chart depicting the meaning of the Title of the Paper 
International Advanced Research Journal in Science, Engineering and Technology

Vol. 7, Issue 10, October 2020

DOI 10.17148/IARJSET.2020.71006

II VACUUM

(THE IMPOSSIBILITY-I)

2.1 Historical aspects: I would like to present things both historically and philosophically. The first and foremost impossibility I would like to mention is that of creating a 'Vacuum'. Niels Marquardt [16] in his extensive paper has started by giving the meaning of 'Vacuum'. The word, 'Vacuum' comes from the Latin word, 'Vacua' which means 'Empty'. Any space containing matter cannot be fully emptied due to which some stray minimum pressure exists. Vacuum can be said to be a region of space (small or big) where the pressure is much below atmospheric pressure. Study of vacuum was as early from the times of the Greeks. It was Aristotle

(384 BC-322 BC) (Fig.4) who claimed that Nature is afraid of total emptiness and that there is an insurmountable "Horror Vacui". Therefore, much before modern physicists, he doubted and even rejected the idea of an absolute vacuum. He assumed, for example, the idea of empty space would invite the concept of motion without resistance, i.e a motion with infinite velocity. This opinion became a paradigm for about 2000 years. Aristotle's idea was believed by famous researchers like Roger Bacon (1214-1299) and Rene Descartes (1596-1650) and had a religious backing from the Church.

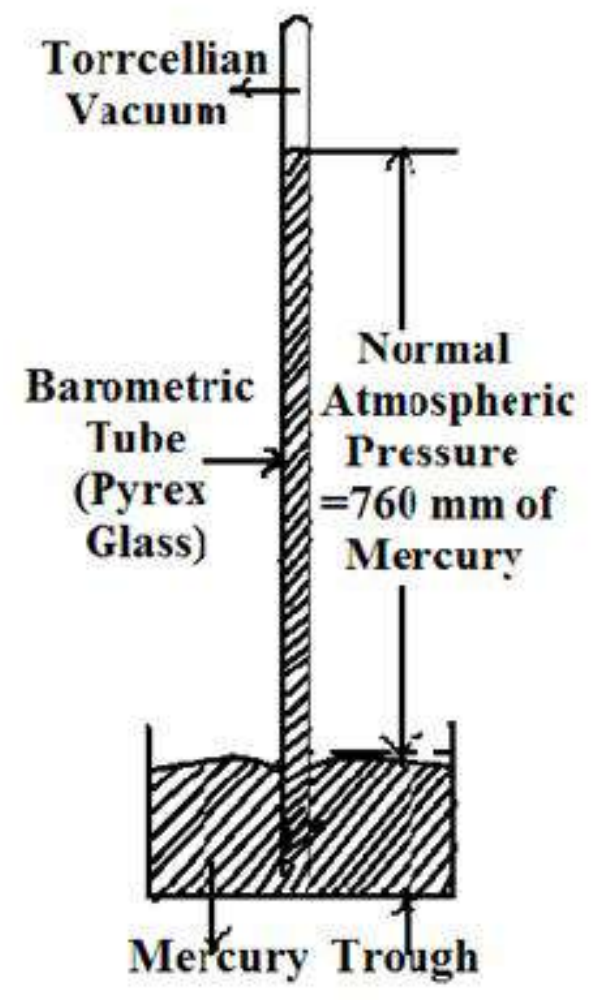

Fig. 2 The Barometer of Torricelli showing the presence of vacuum

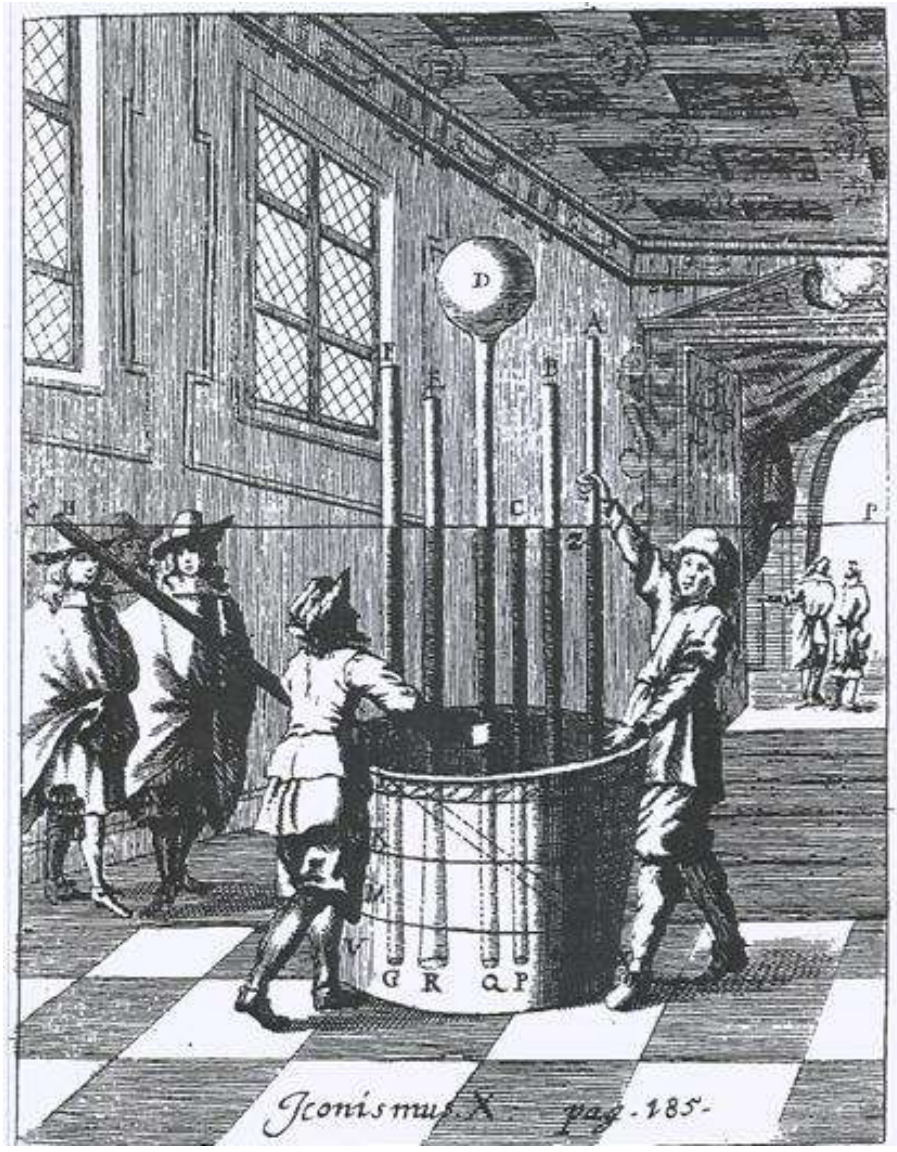

Fig.3 Large scale demonstration by Torricelli using tubes of different sizes also generated Vacuum at the top.[16] 
International Advanced Research Journal in Science, Engineering and Technology

Vol. 7, Issue 10, October 2020

DOI 10.17148/IARJSET.2020.71006

Galileo (1564-1642) (Fig.5) was the first to obtain vacuum using a cylinder and piston. Evangelista Torricelli (1608-1647) (Fig.7) an associate of Galileo succeeded in the year 1644 to produce vacuum experimentally by submerging a glass tube filled with mercury (Fig.2). He demonstrated in 1644 that the mercury column was always $760 \mathrm{~mm}$ above the level of mercury in the trough regardless of size, length, shape or degree of tilt tube as shown in Fig 3 [16]. The French Physicist, Blaise Pascal (1623-1662) (Fig.9) collaborated with Torricelli to measure Atmospheric pressure which in turn helped to find the heights of mountains.

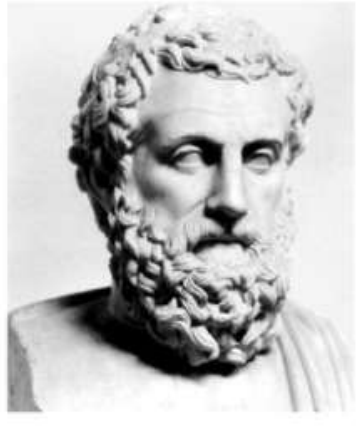

Fig.4 Aristotle (384BC-322BC)

Greek Philosopher

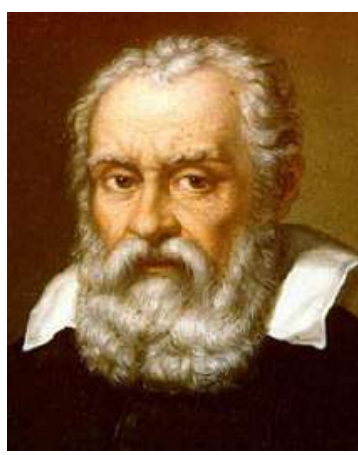

Fig 5 Galileo Galilei $(1564-1642)$

Italian Physicist and astronomer

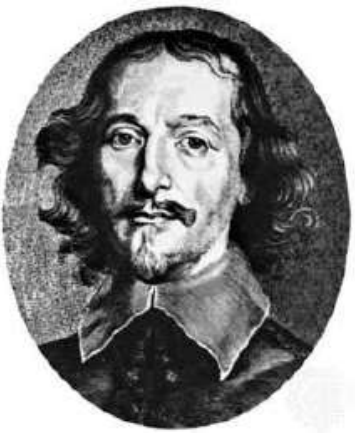

Fig.6 Otto Von Guericke (1602-1686)

German Physicist and Inventor

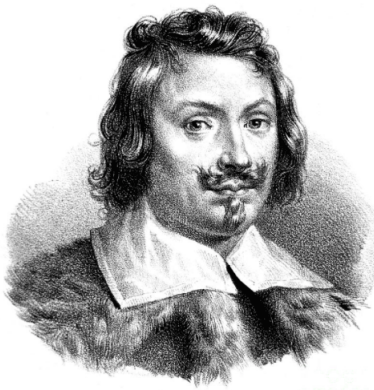

Fig. 7 Evangelista Torricelli (1608-1647) Italian Physicist

The International unit for pressure is the Pascal abbreviated as ' $\mathrm{Pa}$ ' in honor of Blaise Pascal. That is,

$$
1 \mathrm{~Pa}=1 \frac{1 \text { Newton }}{(\text { meter })^{2}}=1 \frac{\mathrm{N}}{\mathrm{m}^{2}}
$$

In the assignment of units, Torricelli is not left out. But his name is shortened to 'Torr'. That is,

Pressure due to $1 \mathrm{~mm}$ of mercury in a barometer $=1$ Torr of pressure

The instrument, Barometer is also shortened to 'Bar' to denote pressure. That is,

1 Bar $=750.062$ Torr $[16]$

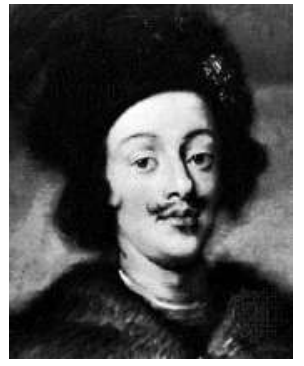

Fig.8 Emperor Ferdinand-III (1608 - 1657)

The Holy Roman Emperor

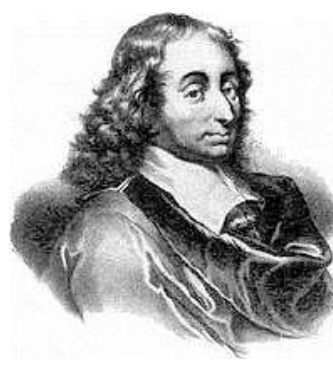

Fig.9 Blaise Pascal $(1623-1662)$ (1627-1691)

French Physicist

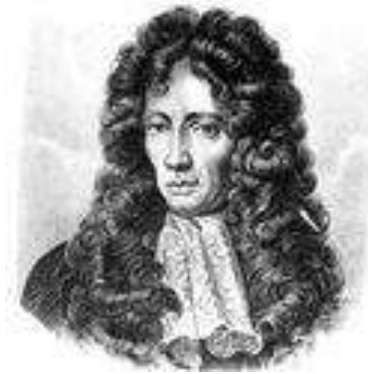

Fig.10 Robert Boyle (1627-1691) Anglo-Irish

Physicist and Chemist
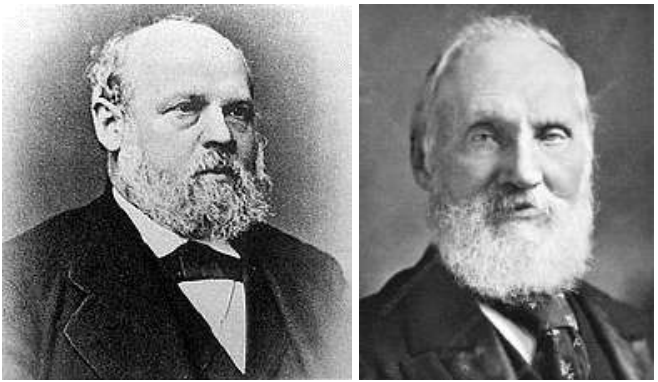

Fig.11 Heinrich Geissler (1814-1879)

German Glass Blower and Chemist
Fig.12 Lord Kelvin (1824-1907) British

Mathematical Physicist 
International Advanced Research Journal in Science, Engineering and Technology

Vol. 7, Issue 10, October 2020

DOI 10.17148/IARJSET.2020.71006

2.2 The Making of the Pump: Otto Von Guericke continued his research in the making of pumps for creating Vacuum. A syringe type of pump used by him to evacuate air from a closed drum is shown in Fig.13 In the year1650 he succeeded in making a cylinder and piston-type vacuum pump shown in Fig.14. It is the

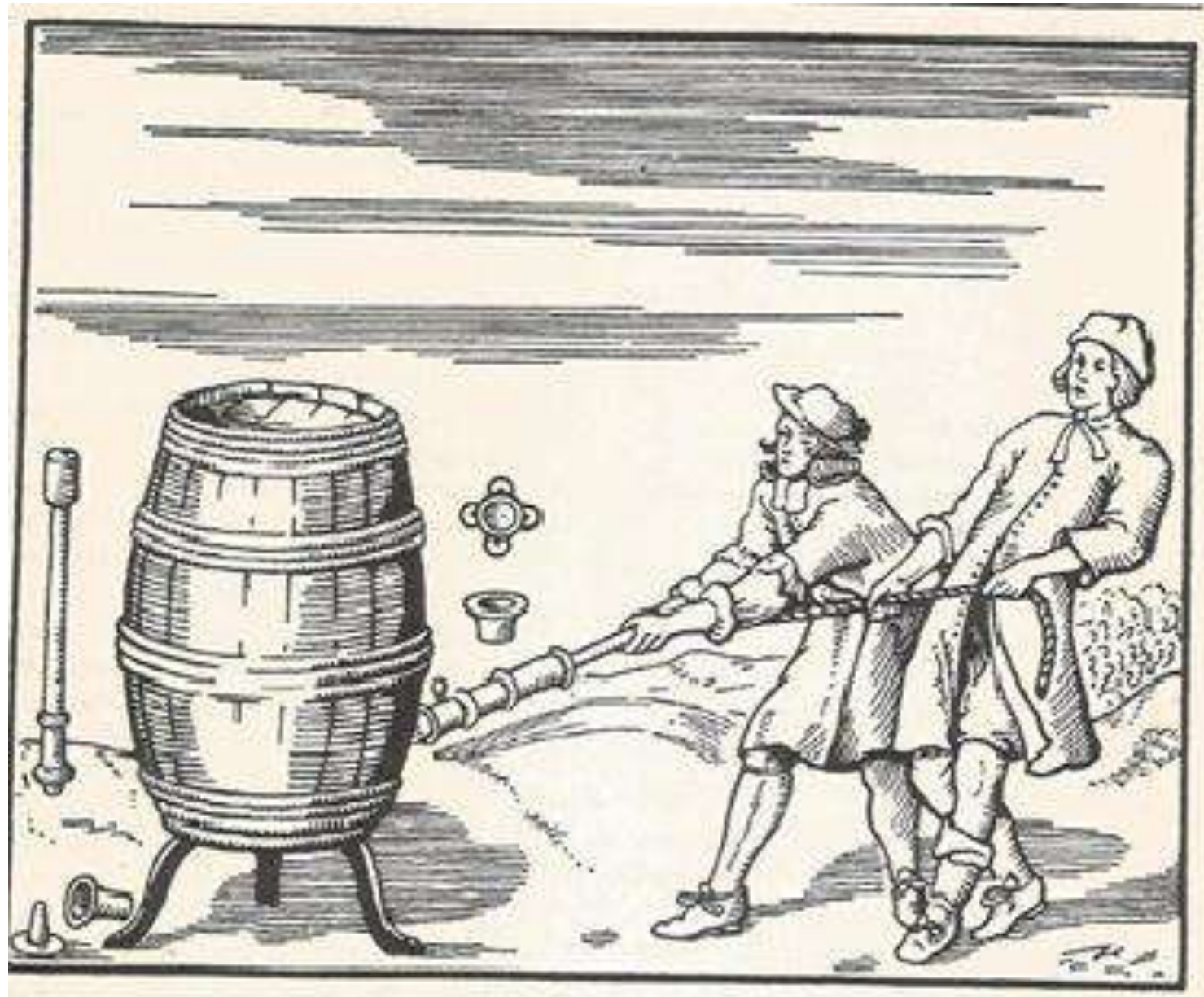

Fig.13 Otto Von Guericke's Vacuum Syringe [26]

prototype used to create vacuum in most of the laboratories. It consists of a vacuum pump connected to, say, a Bell-Jar to be evacuated. The main parts of the pump consists are a metallic cylinder fitted with a piston and handle. At the bottom of the piston there is a valve V1 and at the bottom of the cylinder there is a valve V2. Both the valves close downwards and open upwards in the cylinder. At the top of the cylinder there is a small hole through which the sucked air or gas during evacuation can escape. The pump is connected to the jar by a connecting pipe. For the working of the pump, let us assume that the piston is moved downwards when whatever air in the cylinder escapes through V1 as V2 gets closed. During the upward movement of the piston, V1 gets closed and V2 opens drawing air from the jar through the connecting pipe. Thus during the upward and downward motion of the piston, air from the jar is removed continuously till the pressure in the jar becomes so low that the valve V2 gets closed permanently closed as the atmospheric pressure in the cylinder is greater than the pressure in the jar. 
International Advanced Research Journal in Science, Engineering and Technology

Vol. 7, Issue 10, October 2020

DOI 10.17148/IARJSET.2020.71006

According to physicists, there is no perfect vacuum in the jar. We need some Mathematics to show that perfect vacuum cannot be obtained.

2.3 Mathematics to show that Absolute Vacuum cannot be obtained: In some of my previous papers, I have mentioned about "Foundations and Frontiers" which can be re-written even as "Fundamentals and Frontiers". For a major part of our paper, we are already in the Frontier not knowing our Foundation with Fundamentals. What I mean by that is, we need some elementary algebraic equations given in Karve \& Shah [10] for the working of the pump.

The working of the pump is governed by Boyle's law stated by the Anglo-Irish physicist, Robert Boyle (1627-1691) (Fig.10) of the $17^{\text {th }}$ century. As no temperature changes taking place during the experiment, Boyle's law states that the pressure, $\mathrm{P}$ of a certain quantity of gas is inversely proportional to the volume, $\mathrm{V}$

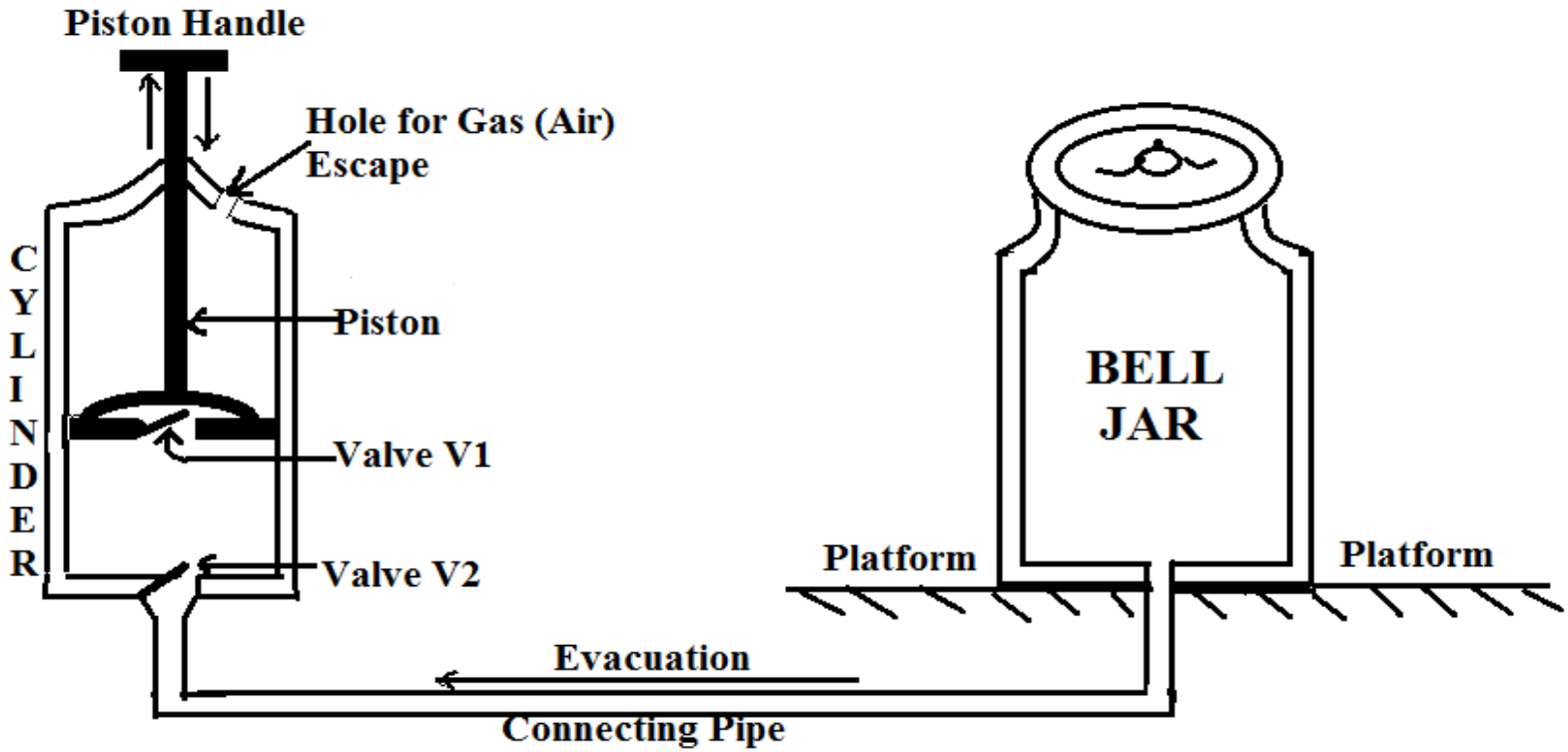

Fig. 14 Illustrative diagram showing the working of a Vacuum Pump (Figure drawn by Author)

occupied by the gas. The law makes the product of $\mathrm{P}$ and $\mathrm{V}$ a constant at constant temperature. This amounts to saying that if $\mathrm{P}_{1}, \mathrm{P}_{2}, \mathrm{P}_{3} \ldots \ldots$ and $\mathrm{V}_{1}, \mathrm{~V}_{2}, \mathrm{~V}_{3}, \ldots \ldots \ldots$ are the corresponding volumes, then

$$
\mathrm{P}_{1} \mathrm{~V}_{1}=\mathrm{P}_{2} \mathrm{~V}_{2}=\mathrm{P}_{3} \mathrm{~V}_{3} \ldots \ldots \ldots \ldots . \mathrm{P}_{\mathrm{n}} \mathrm{V}_{\mathrm{n}}=\text { constant } \ldots \ldots \ldots
$$

Now, coming to our experiment, let $\mathrm{V}$ be the volume of the jar together with the connecting pipe up to the valve V2 and let $\mathrm{v}$ be the volume of air at atmospheric pressure inside the cylinder of the pump up to valve $\mathrm{V} 2$.

Let $\mathrm{P}$ and $\mathrm{V}$ be the pressure and volume respectively of the air before the experiment. Now, when the piston is raised from bottom to top, the volume becomes $(\mathrm{V}+\mathrm{v})$ and pressure in the jar is reduced from $\mathrm{P}$ to say, $\mathrm{P}_{1}$, then as per Boyle's law,

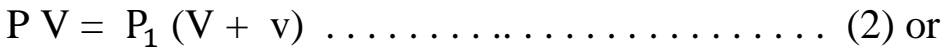

$$
\begin{aligned}
& P_{1}=\frac{P V}{(V+v)}
\end{aligned}
$$


During the downward stroke, the volume $\mathrm{v}$ of the air from the cylinder escapes through the escape hole at the top of the cylinder and a volume $\mathrm{V}$ of air at pressure $\mathrm{P}_{1}$ is left behind in the jar. At the end of the upward stroke again the volume $\mathrm{V}$ at pressure $\mathrm{P}_{1}$ changes to $(\mathrm{V}+\mathrm{v})$ and the pressure changes from $\mathrm{P}_{1}$ to $\mathrm{P}_{2}$ so that

$$
\begin{aligned}
P_{1} V & =P_{2}(V+v) \text { or } \\
P_{2} & =\frac{P_{1} V}{(V+v)}
\end{aligned}
$$

For $\mathrm{P}_{1}$ substitute from equation ( 2a) so that $\quad \mathrm{P}_{2}=\frac{\mathrm{PV}}{(\mathrm{V}+\mathrm{v})} \frac{\mathrm{V}}{(\mathrm{V}+\mathrm{v})}=\mathrm{P}\left[\frac{\mathrm{V}^{2}}{(\mathrm{~V}+\mathrm{v})^{2}}\right]=\mathrm{P}\left[\frac{V}{(\mathrm{~V}+\mathrm{v})}\right]^{2} \ldots$

This is for 2 operations. Proceeding in this way for $\mathrm{n}$ operations of pumping we can write

$$
\mathrm{P}_{\mathrm{n}}=\mathrm{P}\left[\frac{V}{(\mathrm{~V}+\mathrm{v})}\right]^{n}
$$

Proceeding in this way it becomes an unending process of making the pressure inside the jar zero. Deliberately operating the pump further the valves stop functioning damaging its parts. Hence do not think of an absolute vacuum. No physicist on Earth, however clever he may be, cannot succeed in getting absolute vacuum. Can we leave things like that of an unsuccessful situation? Vacuum, as we mentioned earlier, originated from Otto Von Guericke (1602-1686) (Fig.6) of the $17^{\text {th }}$ century. In Physics nothing can be left to Almighty. After several trials, there must be something left out in the Jar and even a single electron is sufficient for an answer. The answer is given by the French physicist, Louis de Broglie (18921987)(Fig.25) and the German theoretical physicist, Werner Heisenberg (1901-1976) (Fig.27) and there lies the real philosophy. We are not in troubled waters and the matter got over when Heisenberg said that 'nothingness' is meaningless. There must be some particle or at least some energy in the Jar. From the point of view of modern particle theory, an electron creates its mirror particle, anti-electron or positron which creates its own field and exist together.

Lloyd W Taylor [18]. Pascal started with the Aristotelian doctrine of the practical and logical impossibility of a vacuum. The rallying cry of this school of thought was Natura abhorret vacuum. As Bishop Morrison, the biographer of Blaise Pascal remarks:

"The error was reinforced in the verbalism that cursed scholastic argument, Vacuum, void, emptiness was identified with nothing, nihil. Rene Descartes (1596-1650) said that if everything should be removed from a vessel, the sides must immediately touch for a vessel cannot be filled with Nothing; that is a logical impossibility, ergo false. The universe, said the thinkers, would sooner fall to pieces than permit an abhorred Nothing in its midst".

\section{GUERICKE'S CRUCIAL TESTS FOR VACUUM}

3.1 Guericke Otto von Air Pressure Experiment: Otto von Guericke's demonstration of the power of air pressure was shown at Regensburg in 1654. A platform was suspended from the bottom of an evacuated sphere made up of two copper hemispheres, and increasing numbers of weights were placed on it as shown in Fig. 15. As the hemispheres were evacuated and sealed, the pressure inside is much less than the atmospheric pressure and hence the hemispheres could not be separated.

3.2 Guericke's Spectacular Demonstration: Otto Von Guericke performed a crucial experiment in May 1654. His studies revealed that light travels through a vacuum but sound does not. In 1654, in a 
International Advanced Research Journal in Science, Engineering and Technology

Vol. 7, Issue 10, October 2020

DOI 10.17148/IARJSET.2020.71006

famous series of experiments that were performed before Emperor Ferdinand-III (1608-1657) (Fig.8) at Regensburg. Guericke. placed two bronze bowls (Magdeburg hemispheres) together to form a hollow sphere about $35.5 \mathrm{~cm}$ (14 inches) in diameter. After he had removed the air from the sphere, 16 horses (8 on each side) were unable to pull the bowls (Fig.16) apart, even though they were held together only by the air around them. The tremendous force that air pressure exerts was thus first demonstrated

Niels Marquardt [16] gives a calculation: He says that we are living on the bottom of a huge ocean of air and that the mass of the atmosphere corresponds to a pressure of about $1 \mathrm{~kg}$ per square $\mathrm{cm}$ or 10 tons on an area of 1 square meter. This is the reason why the 16 horses of Von Guericke were unable to pull the hemispheres apart. The reason why we do not feel anything of this tremendous pressure is simply that there is the same pressure inside our body.

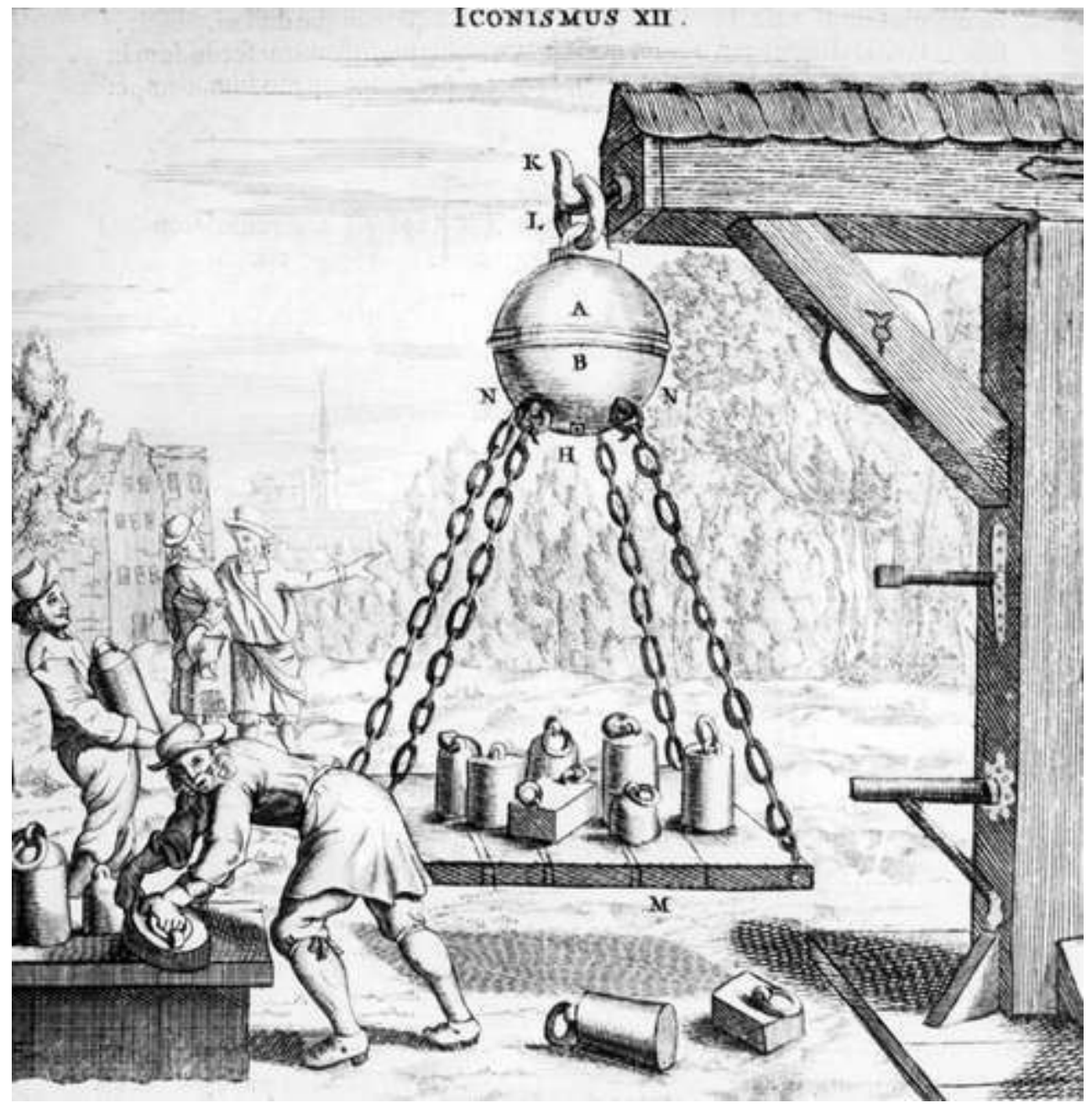

Fig.15 Demonstration of Otto Von Guericke’s Air Pressure Experiment [2]

3.3. The Evolution of Vacuum Pumps: Except some minor changes done in the structure of the pumps, no major changes were done for nearly two centuries by the researchers. The development of vacuum tubes for electronics and the gas discharge tubes needed sufficiently high vacuum and the 
International Advanced Research Journal in Science, Engineering and Technology

Vol. 7, Issue 10, October 2020

DOI 10.17148/IARJSET.2020.71006

researchers had to turn back to the Torricellian method of getting vacuum. It was in 1855 that Heinrich Geissler (1814-1879) (Fig.11) a Physicist and also a skillful glass blower in Bonn, Germany used the Torricelli's method to produce vacuum discharge tubes called Geissler discharge tubes.

The Geissler's apparatus [27] is shown in Fig. 17 in which mechanical plungers such as piston and leather valves were eliminated and the only moving part was a column of mercury. The action of the pump depends uponthe existence of Torricellian vacuum at the top. The operation of the Geissler's apparatus is easily understood from the Fig.17 $\mathbf{A}$ is a glass vessel to be evacuated. $\mathbf{B}$ is a bulb blown at the top of a barometer tube, which is connected to a reservoir of mercury $\mathbf{R}$ by means of a rubber tube $\mathbf{T}$. This reservoir can be raised or lowered by means of a cord and windlass.

3.3.1 Working: With the stop cock, $\mathbf{C}_{2}$ closed and $\mathbf{C}_{1}$ open, $\mathbf{R}$ is raised until the level of mercury reaches $\mathbf{C}_{\mathbf{1}} \cdot \mathbf{C}_{\mathbf{1}}$ is then closed and $\mathbf{R}$ lowered until the mercury level is at $\mathbf{h}$ and $\mathbf{B}$ gets evacuated. $\mathbf{C}_{\mathbf{1}}$ is now opened and the air originally contained in $\mathbf{A}$ is distributed between $\mathbf{A}$ and $\mathbf{B}$. By repeating the above process, the air in $\mathbf{B}$ is

forced out through $\mathbf{C}_{\mathbf{1}}$. In each operation, a certain fractional part of the remaining air in $\mathbf{A}$ is removed. After several hours of slow, patient and monotonous work, a high degree of vacuum can be obtained and that can be judged by the tightness and stiffness of the stop cocks. It is worth noting that some of the earlier discharge tubes and X-Ray tubes were evacuated by this slow and laborious method.

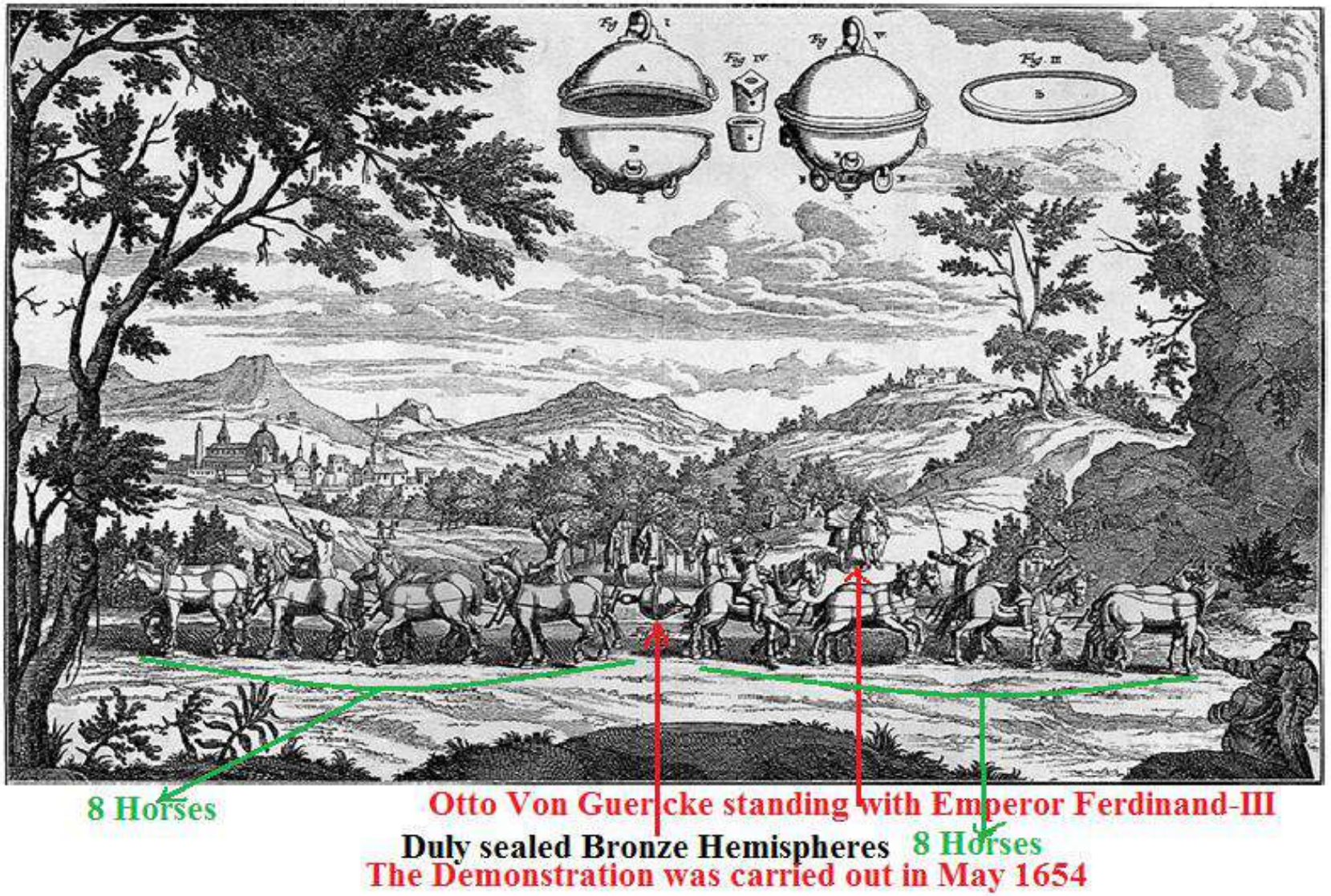

Fig.16 An impressive Demonstration by Otto Von Guericke watched by Emperor Ferdinand-III [16] 
DOI 10.17148/IARJSET.2020.71006

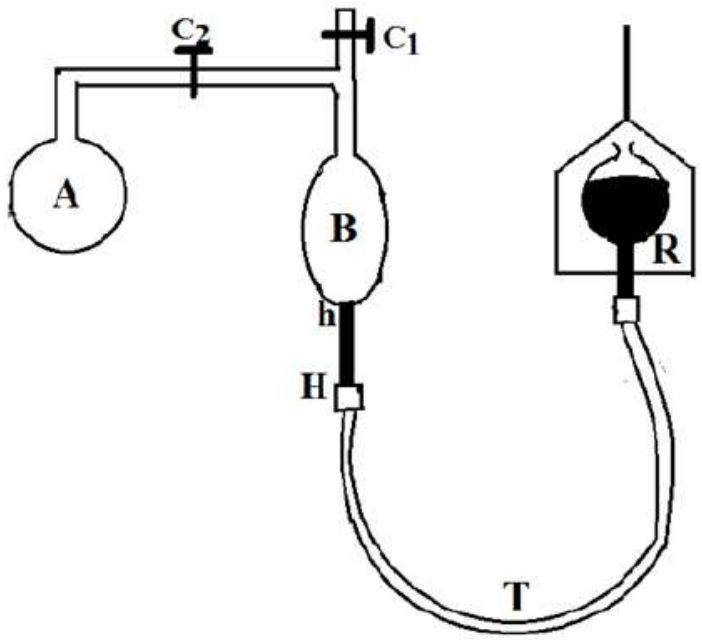

Fig.17 Geissler's Vacuum Pump [27]

3.4 Diffusion Pumps: The beginning of the $20^{\text {th }}$ century, that is, in 1913, the German Physicist, Wolfgang Gaede (1878-1945) (Fig.21) and the American Physicist, Chemist and Engineer, Irving Langmuir (1881-1957) (Fig.24) invented a Diffusion Pump (Fig.23) [1] which has no moving parts and worked very fast in the creationof vacuum. Diffusion pumps are probably the most commonly used mechanisms for creating a high vacuum in industrial vacuum processing. It is also commonly used in mass spectrometry, analytical instrumentation, research and development, and nanotechnology. Since there are no moving mechanical parts, diffusion pumps are extremely reliable and operates practically without noise or vibration. For the same reason, diffusion pumps are relatively low cost to purchase, operate, and maintain

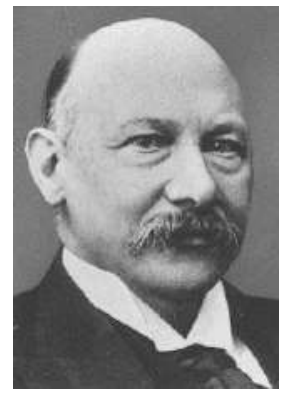

Fig. 18 Heike Kammerlingh Onnes (1853-1926) Dutch Physicist
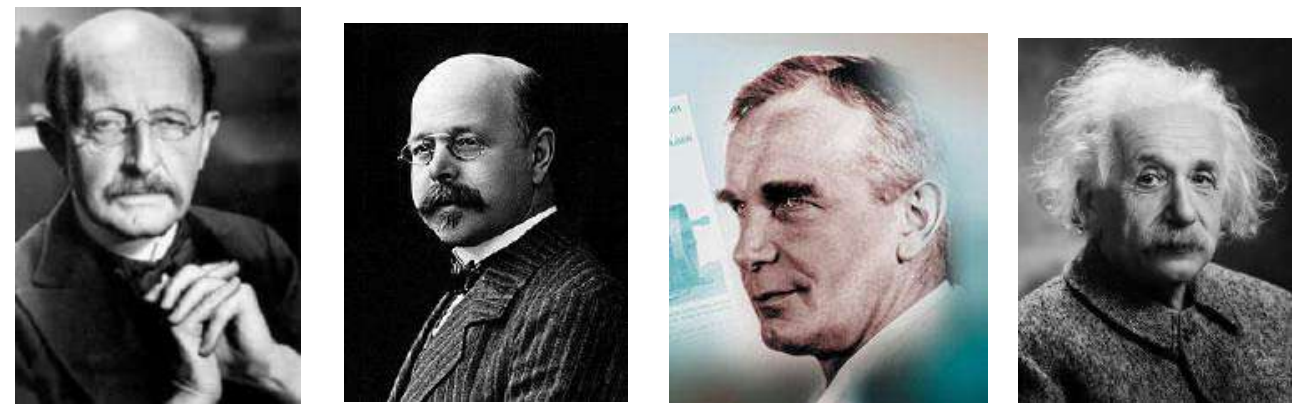

Fig.19. Max Planck Fig.20 Walther Nernst Fig.21Wolfgang Gaede Fig.22Albert Einstein (1858-1947) (1864-1941)

(1878-1945)

(1879-1955)

German Theoretical Physicist
German chemist German Physicist and Pioneer German-born US in Vacuum Engineering Theoretical Physicist

3.4.1 Working Principle: It is also highly effective in producing vacuums $10^{-10}$ to $10^{-2}$ mbar even in poor conditions where reactive gases or gases with excess particles are present. A diffusion pump is a stainless steel chamber that vary in size based on the application. Generally speaking, the interior of diffusion pumps 


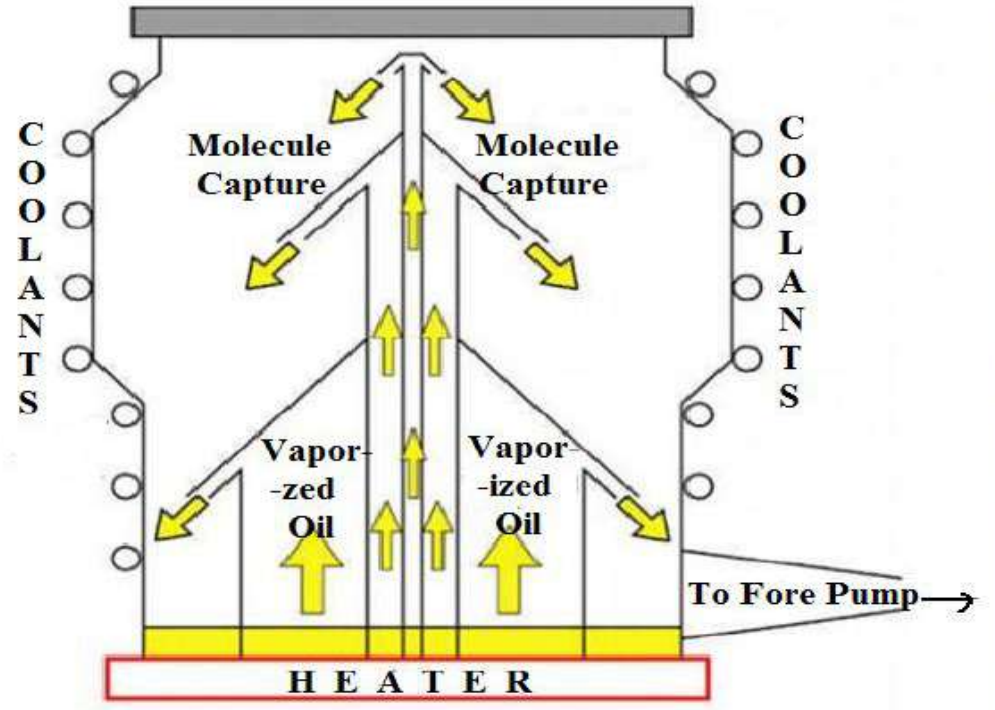

Fig. 23The structure of a Diffusion Pump (Left) [1]

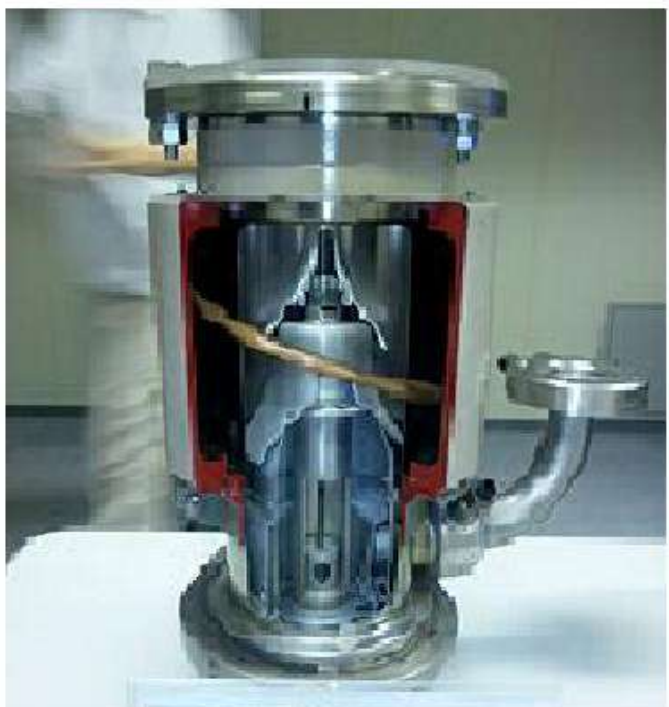

The actual Pump (Right)

(Suitably modified by author)

regardless of size is the same and consist of three varying sized, cone-shaped pressure jets stacked vertically. The lowest stacked cone is the largest and decreases in size as you move upwards representing a shape of an upwards pointing arrow. The very bottom of the chamber is a heater where siliconebased diffusion pump oil is heated until it reaches gaseous state, usually between $180-270^{\circ} \mathrm{C}$. The excited gas travels upward and exits through the pressure jets that are pointed at an downward angle. The downward shooting vapor travels at an incredible 750 miles per hour sometimes breaking the sound barrier, one mach. As the gas travels toward the walls of the pump chamber, it traps air molecules along the way through "diffusion". As the walls of the pump chamber are usually water-cooled, as the gas reaches the chamber walls, it immediately returns to liquid state releasing the trapped air molecules at a lower position and at increased pressure creating the vacuum. The oil drips back to the bottom of the pump chamber where it is heated again.

3.4.2 Standard attainable Vacuum: At present industries have high quality diffusion pumps with which appreciably high level of vacuum can be obtained, Values of vacuum obtained by Giuliano Franchetta GSI Darmstadt, D-64291, Darmstadt, Germany[4] has given Tables (Table-1 and Table-2) for classification of various types of vacuum and also table for examples of particle densities.

Table-1 $[4]$

\section{Classification of various types of Vacuum}

Low Vacuum $\rightarrow$ Atmospheric Pressure to $1 \mathrm{~m}$ bar

Medium Vacuum 1 to $10^{-3} \mathrm{~m}$ bar

High Vacuum (HV) $\quad 10^{-3}$ to $10^{-8} \mathrm{~m}$ bar

Ultra High Vacuum (UHV) $10^{-8}$ to $10^{-12} \mathrm{~m}$ bar

Extreme High Vacuum (XHV) Less than $10^{-12} \mathrm{~m}$ bar
Table-2 [4]

\section{Examples of Particle Densities (Particles $/ \underline{m}^{3}$ )}

Atmosphere $2.5 \times 10^{25}$

Vacuum Cleaner $2 \times 10^{25}$

Freeze Dryer $10^{22}$

Light Bulb $10^{20}$

Thermos Flask $\quad 10^{19}$ 


\section{International Advanced Research Journal in Science, Engineering and Technology}

Vol. 7, Issue 10, October 2020

DOI 10.17148/IARJSET.2020.71006

\section{Relationship}

$$
\begin{aligned}
1 \mathrm{~Pa}=10^{-2} \mathrm{~m} \text { bar } & =7.5 \times 10^{-3} \text { Torr } \\
& =9.87 \times 10^{-6} \mathrm{Atm}
\end{aligned}
$$

TV Tube $10^{14}$

Low Earth Orbit $(300 \mathrm{~km}) 10^{14}$

$\mathrm{H}_{2}$ in $\mathrm{LHC} \sim 10^{14}$

SRS | Diamond $10^{13}$

Surface of Moon $10^{11}$

Interstellar Space $10^{1}$

\section{QUANTUM VACUUM (THE IMPOSSIBILITY-II)}

4.1 The Entry of Quantum: In literature what appears like 'Quantum Vacuum' is a misnomer. As mentioned in section 2.3, first thing is that one cannot obtain absolute vacuum and the question, 'Why it is impossible to obtain? can be answered only in Quantum Mechanics even though Rene Descartes and many thinkers as early as in the $17^{\text {th }}$ century predicted of some calamity that might occur if we totally remove matter from space (Readers must go through the last para in section 2.3). The entry of Quantum will involve, to mention few, eminent physicists such as the French Physicist, Louis de Broglie (18921987) (Fig.25), the German Theoretical Physicist, Werner Heisenberg (1901-1976) (Fig.27) and the Dutch Physicist, Hendrik Casimir (1909-2000) (Fig.33). The explanation using Quantum Mechanics is trivial and will involve both Mathematics and Philosophy the rudiments of which can be seen from the diagram shown in Fig. (28). By Quantum Mechanics, the question of impossibility of obtaining an Absolute Vacuum is not answered, but a solace of saying that something else (matter and energy) exist in that vacuum space. By matter and energy put in the brackets, what I mean is 'particles' and 'fields'. When explained Quantum Mechanically, we may now

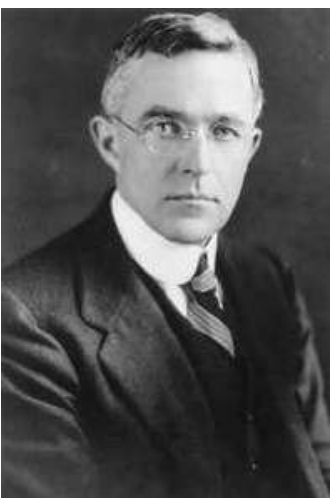

Fig.24 Irwing Langmuir (1881-1957)

US Physicist, Chemist And Engineer

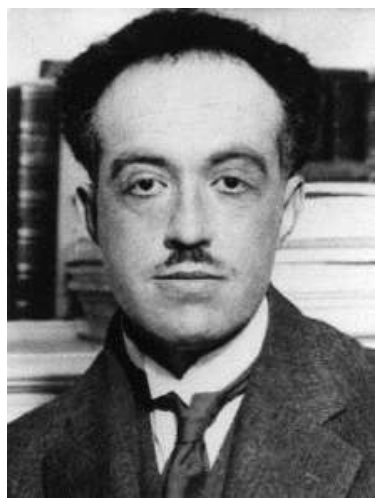

Fig.25 Louis de Broglie (1892-1987)

French Physicist

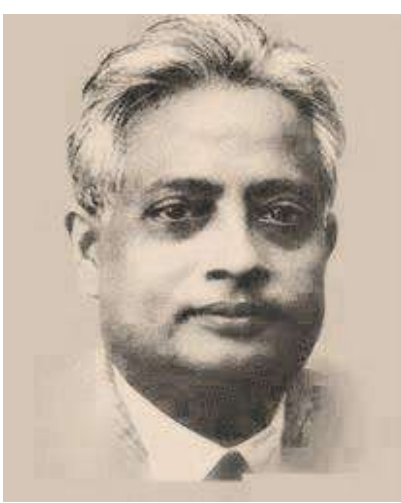

Fig. 26 S.N. Bose (1894-1974) Indian Physicist

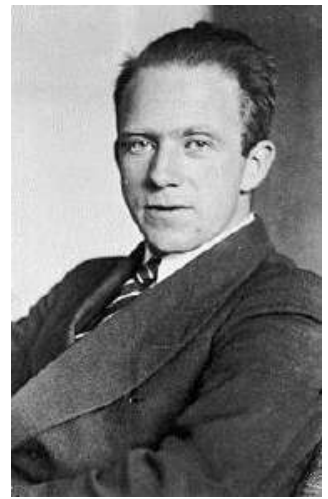

Fig.27 Werner Heisenberg (1901-1976)

German Theoretical Physicist

call any vacuum with such strange particles, 'Quantum Vacuum'. Critically dealing quantum mechanically with a vacuum, will lead us to many new things and something as old as the Big Bang and as new as the particles of the Standard Model 


\section{International Advanced Research Journal in Science, Engineering and Technology}

Vol. 7, Issue 10, October 2020

DOI 10.17148/IARJSET.2020.71006

The mean energy of a Planck oscillator of frequency $v$ at temperature $\mathrm{T}$ is given by

$$
\begin{gathered}
\overline{\mathrm{e}}_{v}=\frac{\mathrm{h} v}{\left(\mathrm{e}^{\mathrm{h} v}-1\right)} \ldots \ldots \ldots \ldots \ldots \ldots \ldots \ldots \ldots \ldots \ldots \ldots \ldots \ldots \ldots
\end{gathered}
$$

On doing so we get

$$
\mathrm{e}^{\frac{\mathrm{h} v}{\mathrm{kT}}}=1+\frac{\mathrm{h} v}{\mathrm{kT}}+\frac{\left(\frac{\mathrm{h} v}{\mathrm{kT}}\right)^{2}}{2}+
$$

Thus, (5) becomes

$$
\overline{\mathrm{e}}_{v}=\frac{\mathrm{h} v}{\left[1+\frac{\mathrm{h} v}{\mathrm{kT}}+\frac{\left(\frac{\mathrm{h} v}{\mathrm{kT}}\right)^{2}}{2}+\ldots \ldots-1\right]}=\frac{\mathrm{h} v}{\left[\frac{\mathrm{h} v}{\mathrm{kT}}+\frac{\left(\frac{\mathrm{h} v}{\mathrm{kT}}\right)^{2}}{2}\right]}=\frac{\mathrm{h} v}{\frac{\mathrm{h} v}{\mathrm{kT}}\left[1+\frac{\mathrm{h} v}{2}\right]}=\frac{\mathrm{kT}}{\left[1+\left(\frac{\mathrm{h} v}{2}\right)\right]} \ldots \ldots
$$

When the denominator of (4) is brought to the numerator, it becomes $\mathrm{kT}\left[1+\left(\frac{\frac{\mathrm{h} v}{\mathrm{kT}}}{2}\right)\right]^{-1}=\mathrm{kT}\left[1-\frac{1}{2}\right.$ $\left.\frac{\mathrm{h} v}{\mathrm{kT}}\right]$ by Binomial expansion

$$
\begin{aligned}
& \therefore \overline{\mathrm{e}}_{v}=\mathrm{kT}-\frac{1}{2} \mathrm{~h} v \\
& \text { Or } \quad \mathrm{kT}=\overline{\mathrm{e}}_{v}+\frac{1}{2} \mathrm{~h} v \\
& \text { That is, } \\
& \mathrm{kT}=\frac{\mathrm{h} v}{\left(\mathrm{e}^{\mathrm{kT}}-1\right)}+\frac{1}{2} \mathrm{~h} v \ldots \ldots \ldots \ldots \ldots \ldots
\end{aligned}
$$

This is the formula obtained by Max Planck (1858-1947) (Fig.19) on the basis of the Quantum Theory for black body radiation in the year 1901. In the year 1911 Planck looked at the equation once again mathematically and thought of expanding the exponential function in the denominator of (5a) in an exponential series. 
International Advanced Research Journal in Science, Engineering and Technology

Vol. 7, Issue 10, October 2020

DOI 10.17148/IARJSET.2020.71006

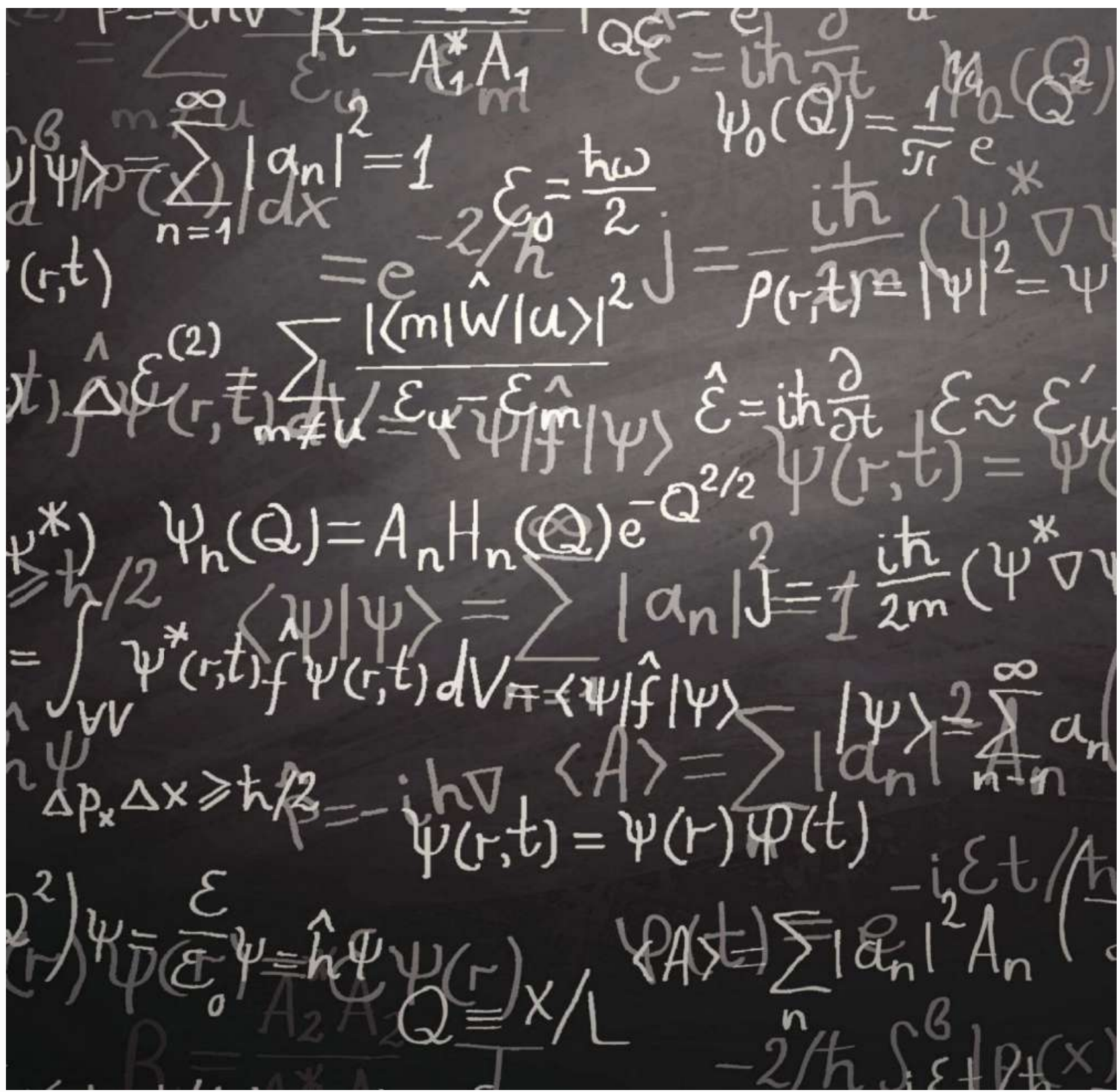

Fig.28 Picture illustrating the jugglery of Quantum Mechanics

J.K. Roberts [21] mentions in his classical book that at high temperatures the energy of an oscillator does not converge towards the value kT predicted by classical mechanics, but towards the value $\mathrm{kT}-\frac{1}{2} \mathrm{~h} v$ as in equation (9). In order to make it converge towards the value $\mathrm{kT}$, it is necessary to assume that an oscillator of frequency $v$ has an amount of energy, $\frac{1}{2} \mathrm{~h} v$ at absolute zero. This is called the Zero Point Energy (ZPE)\}. Thus the Planck's law of radiation takes the form,

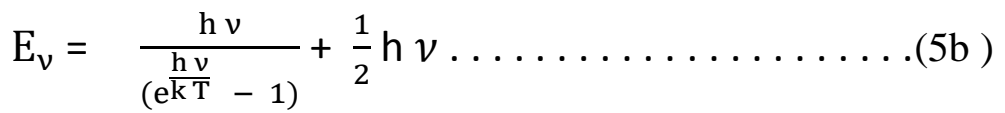


DOI 10.17148/IARJSET.2020.71006

This is the second form of Planck's law which Max Planck presented to the German Physical Society on 3 February 1911. The second term on the right is the ground energy or the Zero Point Energy (ZPE). When $\mathrm{T}=0$, i.e at Absolute Zero,

$$
\mathrm{E}_{0}=\frac{1}{2} \mathrm{~h} v
$$

[Note: The Planck's constant ' $h$ ' is an indivisible constant of value, $6.6256 \ldots . . \times 10^{-34} \mathrm{Js}$. The equation, $\mathrm{E}_{0}=\frac{1}{2} \mathrm{~h} v$ appears to be a misnomer; it is the frequency of whatever radiation at the point in question getting divided and not the Planck's constant. Hence it is ideal and appropriate to write $\mathrm{E}_{v}=\mathrm{h}\left(\frac{v}{2}\right)$. As far as the value is concerned, the value of both the equations remain the same. Further, referring to Lloyd W. Taylor [28] "According to Planck, a vibrating electron in an atom could have amounts of energy equal to $\mathrm{h} v, 2 \mathrm{~h} v, 3 \mathrm{~h} v$ and so forth, but could never have a total energy equal to say, $2.2 \mathrm{~h} v$ or any other non-integral multiple of the fundamental quantum. This concept that energy can be added or removed in finite 'chunks' or quanta.]

Equation, (5b) is the same as equation given by F.K. Richtmyer, E.H. Kennard and John N. Cooper, [20]

When Planck presented the equation, (5b) in 1911, initially there was no total acceptance and considered only the first term on the right without the zero point energy term for the generalization of the Wien's and the Rayleigh-Jean's laws of thermal radiation. This is mainly because the zero-point energy term is independent of temperature. Also, the development of Modern Physics with Quantum Field Theory, Quantum Electrodynamics, Quantum Chromodynamics, Quantum Gravity, and the Theory of Quarks with the Standard Model are all of recent origin and developed from the later half of the $20^{\text {th }}$ century

4.2 Zero Point Energy (ZPE): Many physicists started investigating the authenticity of the $\frac{1}{2} \mathrm{~h} v$ term appearing in the Planck's law of black body radiation. The question raised by some in thirties as to getting a similar term by using the Uncertainty Principle of Heisenberg which he formulated in 1927. I would like to present a method to arrive at this Zero Point Energy term, $\frac{1}{2} \mathrm{~h} v$ by using the Uncertainty Principle.

4.2.1 ZPE using Uncertainty Principle: The energy, E of a quantum harmonic oscillator must be at least

$$
\mathrm{E}=\frac{(\Delta p)^{2}}{2 m}+\frac{1}{2} \mathrm{~m} \omega^{2}(\Delta x)^{2} \ldots \ldots \ldots \ldots \ldots \ldots
$$

Where $\Delta x$ and $\Delta p$ are the uncertainties in position and momentum respectively. Taking the lower limit from the Uncertainty Principle,

$$
\Delta x \Delta \mathrm{p}=\frac{\hbar}{2}
$$

where $\hbar$ is the reduced Planck's constant, $\frac{h}{2 \pi}$. With this the energy, E can be written

$$
\mathrm{E}=\frac{\hbar^{2}}{8 m(\Delta x)^{2}}+\frac{1}{2} \mathrm{~m} \omega^{2}(\Delta x)^{2} \ldots \ldots \ldots \ldots \ldots \ldots \ldots \ldots
$$




\section{International Advanced Research Journal in Science, Engineering and Technology}

Vol. 7, Issue 10, October 2020

DOI 10.17148/IARJSET.2020.71006

Minimizing this energy by taking the derivative with respect to the position uncertainty and setting it equal to zero gives,

$$
\begin{aligned}
-\left[\frac{\hbar^{2}}{4 m(\Delta x)^{3}}\right] & +\mathrm{m} \omega^{2} \Delta x=0 \text { That is, } \\
\mathrm{m} \omega^{2} \Delta x & =\left[\frac{\hbar^{2}}{4 m(\Delta x)^{3}}\right] \\
\mathrm{m} \omega^{2} & =\left[\frac{\hbar^{2}}{4 m(\Delta x)^{4}}\right] \\
(\Delta x)^{4} & =\frac{\hbar^{2}}{4 m^{2} \omega^{2}} . \text { That is, } \\
(\Delta x)^{2} & =\frac{\hbar}{2 m \omega} \\
\Delta x & =\sqrt{\frac{\hbar}{2 m \omega}} \ldots \ldots \ldots \ldots . . .
\end{aligned}
$$

or

or

Substituting this value of $\Delta x$ in equation (2) gives

$$
\begin{aligned}
\mathrm{E}_{0} & =\frac{\hbar^{2}}{8 m\left(\frac{\hbar}{2 m \omega}\right)}+\frac{1}{2} \mathrm{~m} \omega^{2}\left(\frac{\hbar}{2 m \omega}\right) \\
& =\frac{\hbar \omega}{4}+\frac{\hbar \omega}{4}=\frac{1}{2}(\hbar \omega)
\end{aligned}
$$

$$
\begin{aligned}
\text { Now, } \hbar & =\frac{h}{2 \pi} ; \omega=2 \pi v \\
\therefore \quad \mathrm{E}_{0} & =\left(\frac{1}{2}\right)\left(\frac{h}{2 \pi}\right)(2 \pi v)=\frac{1}{2} \mathrm{~h} v . \text { That is, } \\
\mathrm{E}_{0} & =\frac{1}{2} \mathrm{~h} v \ldots \ldots \ldots \ldots
\end{aligned}
$$

Is the Zero Point Energy (ZPE)

4.3 Energy Levels of a Quantum Harmonic Oscillator: Various energy levels for a Quantum Harmonic Oscillator is shown Fig. 29 (Figure suitably modified from original) 
International Advanced Research Journal in Science, Engineering and Technology

Vol. 7, Issue 10, October 2020

DOI 10.17148/IARJSET.2020.71006

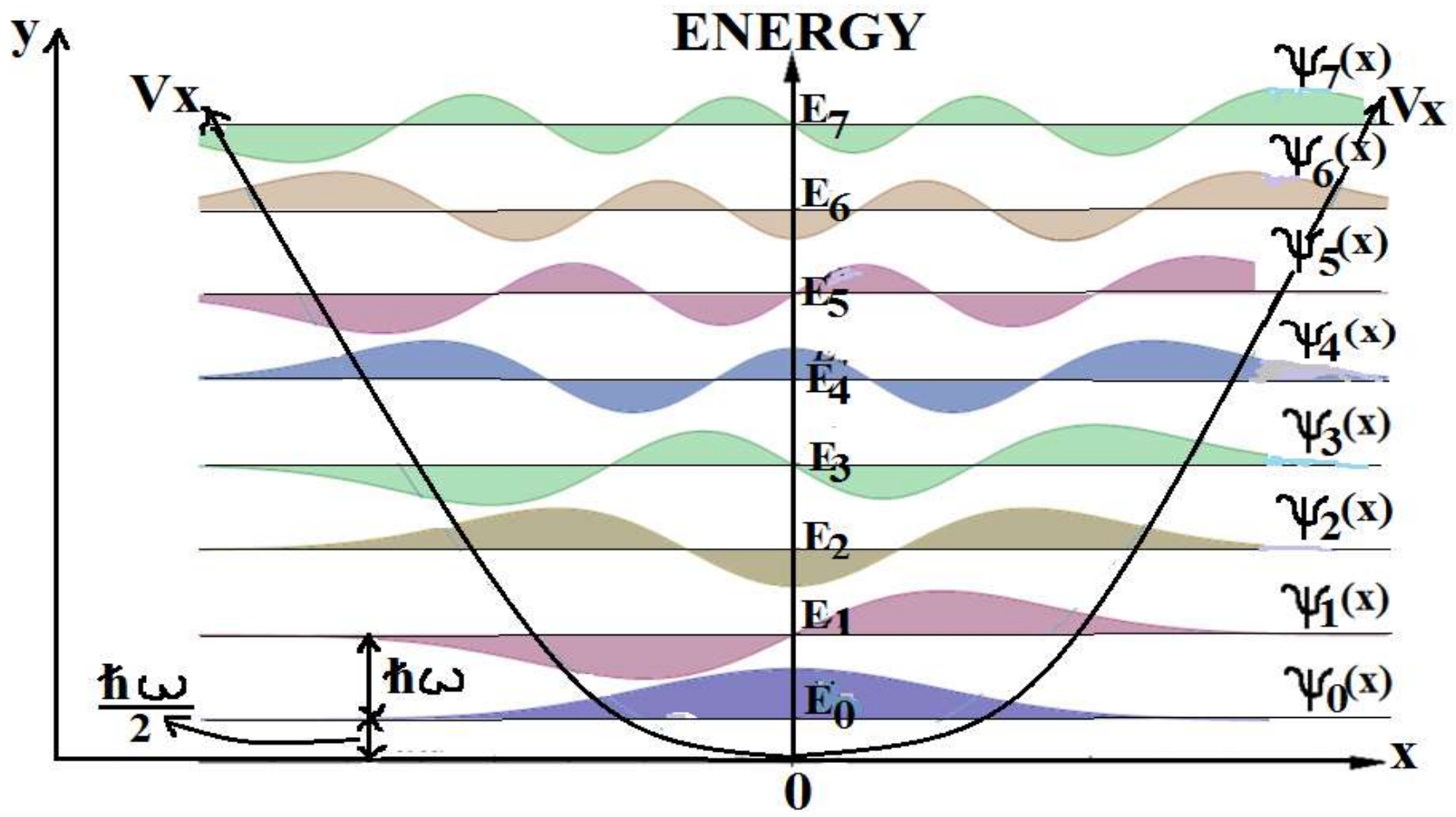

Fig.29 The first seven wave functions of the quantum harmonic oscillator.

4.3.1 What is after all inside the Quantum Vacuum? John Gribbin [9] makes an interesting reading about Quantum Vacuum making it more clear even for a non-physicist. The author says $t$ hat " in Quantum Physics, 'Vacuum' is not nothing at all, but seethes with activity. Thanks to Quantum Uncertainty, virtual particles are constantly being produced and disappearing. A good way to think of a vacuum is as superposition of states for many different kinds of field. To keep things simple, think first of just one kind of field, the electromagnetic field. The different states of the field are like the different notes that can be obtained from a single plucked guitar string. Like the energy levels of an electron in an atom, they form a kind of energy staircase, with the steps spaced out at distances corresponding to the energy of a single photon. When an atom emits a photon, the energy of the corresponding frequency of the vacuum field is increased by one unit. Matching the decrease in energy of the atom. The temporary appearance of a virtual photon corresponds to the field energy moving up a step all by itself, and then falling back again, like a guitar that plays random notes all by itself. The author, further says that:

In addition to the electromagnetic field, in all its states, you have to imagine also a field for electrons, one for protons, and so on for every kind of particle therein. Each of these vacuum fields exists in a superposition of many states. All such fields fill the universe in its formation making it very manystringed instrument. Thus, vacuum is the lowest energy state of space-time filled with fields."

From the second table of particle densities given in section 3.4.2 one can understand the number of particles in unit volume. As energy is associated with each particle, the energy density is also of interest. John A. Maken [6] starts by quoting John Archibald Wheeler who said:

"Empty space is not empty." However, there are many different models of the energy content of the vacuum. One extreme position is that the only energy density present in the vacuum is dark energy which is about $6 \times 10^{-10} \mathrm{~J} / \mathrm{m}^{3}$. The standard model has 17 named particles and each particle has its own field which fills all of space=time. For example, the Higgs field is one of these fields and the energy density 
DOI 10.17148/IARJSET.2020.71006

of this field has been estimated at about $10^{46} \mathrm{~J} / \mathrm{m}^{3}$. Quantum chromodynamics also requires energy density at least this high. Field theory has zero point energy where the vacuum is assumed to have harmonic oscillators with energy $E=1 / 2 \hbar \omega$ where all frequencies up to Planck frequency are represented. This implies Planck energy density equal to about $10^{113} \mathrm{~J} / \mathrm{m}^{3}$. This is often assumed to be impossible, but the argument can be made that general relativity implies that space-time has impedance equal to $c^{3} / G \approx 4 \times 10^{35} \mathrm{~kg} / \mathrm{s}$. This tremendously large impedance is consistent with the vacuum having Planck energy density"

Stephen Battersby, [24] reports in the New Scientist:

"It's confirmed: Matter is merely vacuum fluctuations"

Lynn Cominsky [12] equates Vacuum Energy with Dark Energy as shown in her following illustration (Fig.30)

NASA [15] WMAP determined that the universe is flat, from which it follows that the mean energy density in the universe is equal to the critical density (within a $0.5 \%$ margin of error). This is equivalent to a mass density of $9.9 \times 10^{-30} \mathrm{~g} / \mathrm{cm}^{3}$, which is equivalent to only 5.9 protons per cubic meter. Of this total density, we now (as of January 2013) know the breakdown to be:

- $4.6 \%$ Atoms. More than $95 \%$ of the energy density in the universe is in a form that has never been directly detected in the laboratory! The actual density of atoms is equivalent to roughly 1 proton per 4 cubic meters.

- 24\% Cold Dark Matter. Dark matter is likely to be composed of one or more species of subatomic particles that interact very weakly with ordinary matter. Particle physicists have many plausible candidates for the dark matter, and new particle. This is illustrated in Fig. 31.

4.4 The Largest Vacuum ever made: With a total of 104 kilometers of piping under vacuum, the vacuum system of the Large Hadron Collider (LHC) at Geneva is among the largest in the world. The insulating vacuum, equivalent to some $10^{-6}$ mbar, is made up of an impressive $50 \mathrm{~km}$ of piping, with a combined volume of 15,000 cubic meters, more than enough to fill the nave of a cathedral. Building this vacuum system required more than 250,000 welded joints and 18,000 vacuum seals. The remaining 54 $\mathrm{km}$ of pipes under vacuum are the beam pipes, through which the LHC's two beams travel. The pressure in these pipes is in the order of $10^{-10}$ to $10^{-11}$ mbar, a vacuum almost as rarefied as that found on the surface of the Moon. The LHC's vacuum systems are fitted with 170 Bayard-Alpert ionization gauges and 1084 Pirani and Penning gauges to monitor the vacuum pressure. More descriptions regarding the vacuum in the LHC are intentionally cut short in order to maintain brevity of this research paper. To put matter in a nut-shell, literature mentions that the vacuum in the LHC is thinner than the interstellar void.

4.5 Experimental Proof for particles and fields in Quantum Vacuum:Quantum uncertainty allows energy to appear spontaneously from nothing as long as it disappears again swiftly. Since matter is a form of energy, one has to consider both annihilation of matter and materialization of energy. Empty space has to be thought of as seething with 'virtual particles' really meaning particle-antiparticle pairs which exist only fleetingly before disappearing again. 
International Advanced Research Journal in Science, Engineering and Technology

Vol. 7, Issue 10, October 2020

DOI 10.17148/IARJSET.2020.71006

4.5.1 The Casimir Effect: John Gribbin [8] mentions that the easiest particles to make are photons as they do not have rest mass. In the 1940's Dutch physicist, Hendrik Casimir (1909-2000) (Fig.33) suggested an experiment to measure the influence of these virtual photons. If two metal plates are placed close together, face to face, the virtual photons of the Quantum Vacuum in the gap between the plates will bounce between the highly reflective surfaces of the plates. The plates will be pulled together as shown in the Fig.32.[30]

\section{Vacuum Energy = Dark Energy?}

The cosmological constant $\Lambda$ may be related to the "zero-point energy" of the Universe which comes from the quantum fluctuations of the vacuum.

However, the vacuum energy density is $10^{120}$ too high to allow structure formation to occur

- Something must be canceling almost all of the vacuum energy in order for us to be here

- And that something must have arranged for the $\sim 73 \%$ of critical density to be left over at our current time, 13.7 billion years later

Fig.30 Illustration of Vacuum Energy with Dark Energy [12]

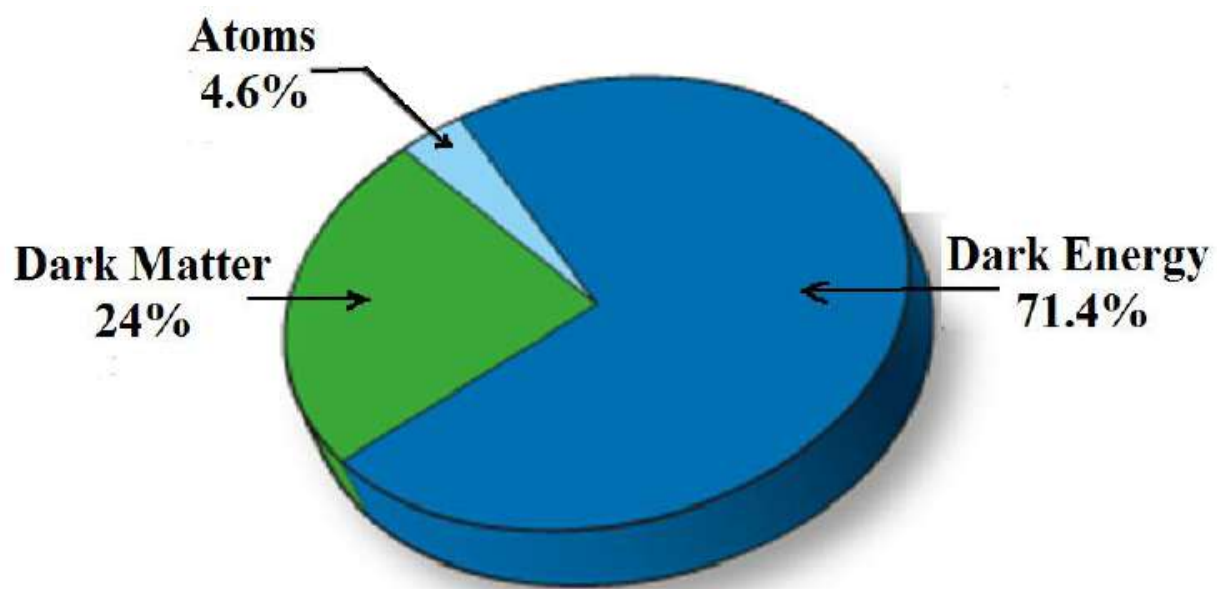

Scenario as on Today

Fig.31 The distribution in the Universe 
DOI 10.17148/IARJSET.2020.71006

The plates will experience an attractive force because the photons are wavelengths of light making an analogy with the vibrations of a plucked guitar string as it is fixed at one point and can vibrate only with certain frequencies or wavelengths. In the same way, photons of light with certain wavelengths will fit neatly into the gap between the two metal plates 'fixed' each end. This means that all other possible wavelengths are excluded from the gap and hence there are fewer photons in each cubic centimeter of vacuum between the plates than there are in the vacuum outside. So, in effect, there is an excess pressure from outside pushing the plates together.

Trang T Nguyen [29] derived the force, $\mathrm{F}$ and energy $\mathrm{E}$ of the plates the equations for which are given below:2

$$
\begin{aligned}
\mathrm{F} & =\frac{\pi^{2}}{240} \frac{\hbar c}{\mathrm{~L}^{4}} \mathrm{~A} \\
\text { and the Energy } \mathrm{E} & =\frac{\pi^{2}}{720} \frac{\hbar c}{\mathrm{~L}^{3}} \mathrm{~A}
\end{aligned}
$$

where

$\hbar$ is the reduced Planck's constant, $\mathrm{c}$ the velocity of light, L the distance between the plates and A the area of the plates.

Peter W. Milonni [17] mentions that the zero-point energy density of the vacuum, due to all quantum fields, is extremely large, even when we cut off the largest allowable frequencies based on plausible physical arguments. It implies a cosmological constant larger than the limits imposed by observation by about 120 orders of magnitude. This "cosmological constant problem" remains unresolved.

From this line of reasoning, quantum physics predicts that all of space must be filled with electromagnetic zero-point fluctuations (also called the zero-point field), creating a universal sea of zeropoint energy. The $\hbar$ density of this energy depends critically on where in frequency the zero-point fluctuations cease. Since space itself is thought to break up into a kind of quantum foam at a tiny distance scale called the Planck scale $\left(10^{-33}\right.$ centimeters), it is argued that the zero-point fluctuations must cease at a corresponding Planck frequency $\left(10^{43}\right.$ hertz $)$. If this is the case, the zero-point energy density would be 110 orders of magnitude greater than the radiant energy at the center of the Sun.

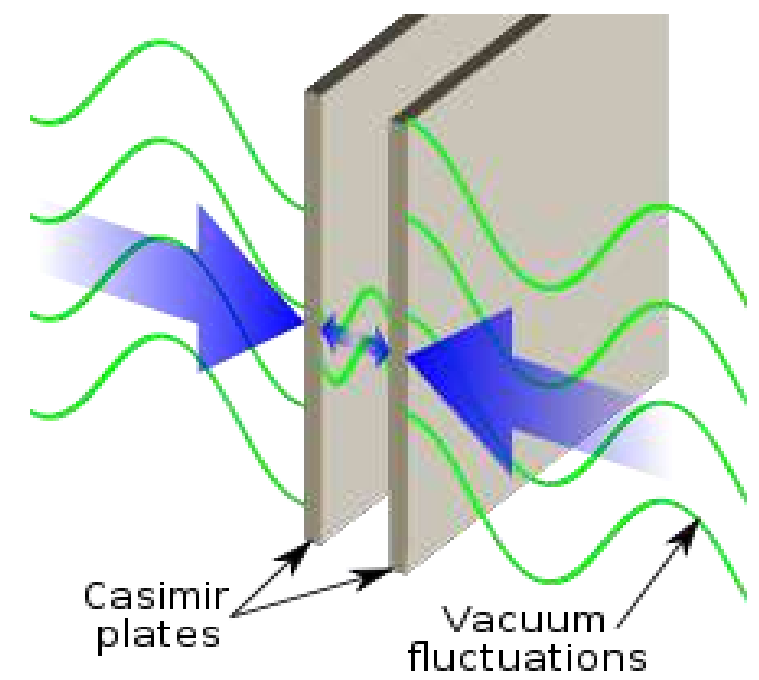

Fig.32 Illustration of Casimir Effect [28,30] 


\section{International Advanced Research Journal in Science, Engineering and Technology}

Vol. 7, Issue 10, October 2020

DOI 10.17148/IARJSET.2020.71006

Liquid helium-4 is a great example: Under atmospheric pressure, even at absolute zero, it does not freeze solid and will remain a liquid. This is because its zero-point energy is great enough to allow it to remain as a liquid, even if a very cold one. Everything everywhere has a zero-point energy, from particles to electromagnetic fields, and any other type of field. Combine them all together and you have the vacuum energy, or the energy of all fields in space

Scientific American [23] It is generally true that the amount of energy in a piece of vacuum can be altered by material around it, and the term "Casimir Effect" is also used in this broader context. If the mirrors (plates) move rapidly, some of the vacuum waves can become real waves. Julian Schwinger and many others have suggested that this "dynamical Casimir effect" may be responsible for the mysterious phenomenon known as sonoluminescence.

John Baez's Stuff [7] gives answers to the question, "What's the Energy Density of the Vacuum?

1. The absolute value of mass density is less than $10^{-26}$ kilograms per cubic meter. In terms of energy density, this is about $10^{-9}$ joules per cubic meter.

2. recent measurements by the Wilkinson Microwave Anisotropy Probe (WMAP) and many other experiments seem to be converging on a positive cosmological constant, equal to roughly $7 \times$ $10^{-27}$ kilograms per cubic meter. This corresponds to a positive energy density of about $6 \times 10^{-}$ ${ }^{10}$ joules per cubic meter.

3. One way to put it is that in units of Planck mass per Planck length cubed, the cosmological constant is about $10^{-123}$. It's hard to make up a theory that explains such a tiny nonzero number.

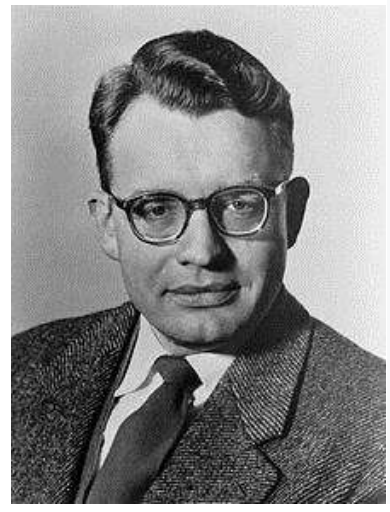

Fig.33 Hendrik Casimir (1909-2000) Dutch Physicist

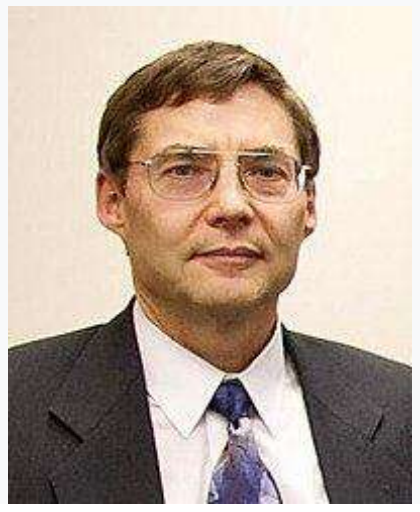

Fig.34 Carl Wieman (Born:: 1951) US Physicist

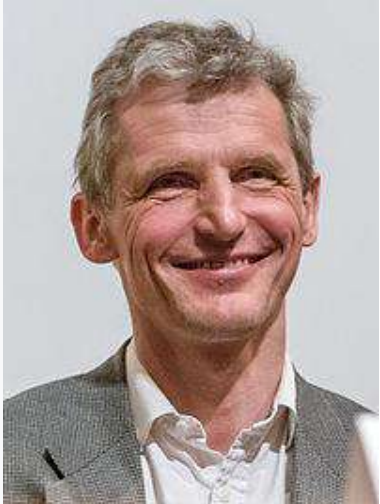

Fig.35 Wolfgang ketterie (Born: 1957) US Physicist

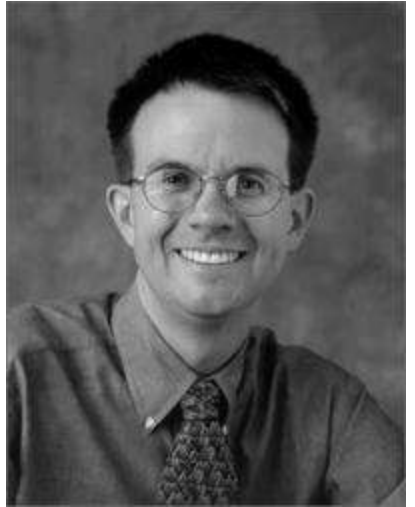

Fig.36 Eric Allin Cornell (Born : 1961) US Physicist 
International Advanced Research Journal in Science, Engineering and Technology

Vol. 7, Issue 10, October 2020

DOI 10.17148/IARJSET.2020.71006

\section{THE BOSE-EINSTEIN CONDENSATE (ABSOLUTE ZERO) (THE IMPOSSIBILITY III)}

5. Earlier Work: The study of Low-Temperature Physics started right from the time of Robert Boyle (1627-1691) (Fig.10) the Anglo-Irish natural philosopher, Chemist, Physicist and inventor. He was the first

scientist to study 'Cold' With whatever equipment available, attaining a temperature some 250 degrees below $0^{\circ} \mathrm{C}$ was not possible. The problems with the scientists of the $17^{\text {th }}$ and $18^{\text {th }}$ centuries were lack of techniques to approach the Absolute Zero $\left(0^{0} \mathrm{~K}\right.$ or $\left.-273.16^{\circ} \mathrm{C}\right)$. But, later eminent physicists such as the British Physicist,

William Thomson also known as Lord Kelvin(1824-1907) (Fig.12), the Dutch Physicist, Heike Kamerlingh Onnes (1853-1926) (Fig.8) and many others started their work by cooling Helium which boils at a temperature of about $-269^{\circ} \mathrm{C}$ which is some 4 degrees above absolute zero.. The situation here is something like Zero Point Energy (ZPE). One may go very near to it, but cannot attain that temperature and that is the real IMPOSSIBILITY. Only rare things are IMPOSSIBLE for physicists and they have somehow made it FEASIBLE and what I mean by that is, three US Physicists, Carl Wieman (b.1951. . .) (Fig.34), Wolgang Ketterie (b. 1957. . .) (Fig.35) and Erie Allin Cornel (b. 1961 . .) (Fig.36) could go very near to absolute zero surprisingly so near to a temperature of even Nano Kelvin $\left(\left(\mathbf{1 0}^{-\mathbf{9}}\right)^{\mathbf{0}} \mathrm{K}\right.$.. Table-3 shows the work carried out by scientists to approach Absolute Zero right from the beginning of the $18^{\text {th }}$ century till date. The sections that follow will deal with the theory related to this IMPOSSIBILITY.

In one of my previous papers, Nair V.C.A [14], I have elaborately presented both the Impossibilities III and IV and the same I would like to reproduce here with minor changes. Let us start with the Bose Condensation.

5.1.The Bose Condensation: An Indian physicist, Satyendra Nath Bose (1894-1974) (Fig.26) working on Quantum Statistics of elementary particles wrote a paper in which he derived Planck's law of radiation without Classical Mechanics. He felt that the ideal scientist to appreciate his paper at his time was Albert Einstein (1879-1955) (Fig.22) So on June 4, 1924, Bose sent his paper directly to Einstein, writing:

"I have ventured to send you the accompanying article for your perusal and opinion. I am anxious to know what you think of it. You will see that I have tried to deduce the coefficient $8 \pi v^{2} / c^{3}$ in Planck's Law independent of the classical electrodynamics

Einstein instantly saw that Bose's work was very valuable, although even he did not see its full farreaching significance at first - this took him a few days. Planck's quantum law actually contained a factor from classical physics: $8 \pi v^{2} / \mathrm{c}^{3}$. The mixing of classical and quantum theories in one equation had been a perpetual source of discomfort for physicists working in the field

Bose had been able to produce the $8 \pi v^{2} / \mathrm{c}^{3}$ factor without using classical physics. Instead the factor arose naturally from the argument that photons with equal energy were indistinguishable from one another. 
International Advanced Research Journal in Science, Engineering and Technology

Vol. 7, Issue 10, October 2020

DOI 10.17148/IARJSET.2020.71006

Einstein translated Bose's work into German and arranged for it to be published in the journal Zeitschrift für Physik. Einstein replied to Bose on July 24, saying that Bose's work was: an important step forward and I liked it very much

5.2.The Judgment of History: Bose's paper is now recognized as one of the most important theoretical papers in the founding of quantum theory. In fact, Bose had founded an entire new field: quantum statistics.

Einstein was impressed, and said that he liked it very much. Einstein translated the paper himself from English to German and submitted it for Bose to the Zeitschrift für Physik, which published it in 1924. (The Einstein manuscript, once believed to be lost, was found in a library at Leiden University in 2005.). Einstein then extended Bose's ideas to matter in two other papers. The result of their efforts is the concept of a Bose gas, governed by Bose-Einstein statistics, which describes the statistical distribution of identical particles with integer spin, now called bosons. Bosons, which include the photon as well as atoms such as helium-4 $\left({ }^{4} \mathrm{He}\right)$, are allowed to share a quantum state. Einstein proposed that cooling bosonic atoms to a very low temperature would cause them to fall (or "condense") into the lowest accessible quantum state, resulting in a new form of matter, the Fifth State, called Bose-Einstein Condensate.

We follow the literature given by Kompaneyets [11] and Richard Fitzpatrick [19]. The material to be cooled is Helium with an atomic number 2 and atomic mass 4 and hence denoted by ( $\left.2^{\wedge} 4\right)$ He.. Helium has peculiar properties at low temperatures. Both the electrons in the cloud of helium atom and the protons and neutrons in the nucleus are in the 1 s state.

Table -3

\begin{tabular}{|c|c|c|c|c|c|}
\hline $\begin{array}{c}\text { Sr. } \\
\text { No. }\end{array}$ & Year & $\begin{array}{c}\text { Temperature } \\
\text { Degree Kelvin }\end{array}$ & $\begin{array}{c}\text { Experiment or } \\
\text { Discovery }\end{array}$ & $\begin{array}{c}\text { Name/s of } \\
\text { Scientists involved }\end{array}$ & Country \\
\hline 1 & 724 & $233^{0} \mathrm{~K}$ & Cascade Series & Gabriel Fahreheit & Netherlands \\
\hline 2 & 834 & $163^{0} \mathrm{~K}$ & $\begin{array}{c}\text { Mixture of Dry Ice, } \\
\text { Snow and Ether }\end{array}$ & $\begin{array}{c}\text { Charles Thilorier, } \\
\text { France }\end{array}$ & France \\
\hline 3 & 877 & $133^{0} \mathrm{~K}$ & $\begin{array}{c}\text { Droplets of Liquid } \\
\text { Oxygen }\end{array}$ & $\begin{array}{c}\text { Raoul Pictet, } \\
\text { /Louis Cailletet, }\end{array}$ & $\begin{array}{c}\text { Geneva } \\
\text { France }\end{array}$ \\
\hline 4 & 1883 & $90^{0} \mathrm{~K}$ & $\begin{array}{c}\text { Measurable quantity of } \\
\text { Liquid Oxygen } \\
\text { Wroblewski \& Karol } \\
\text { Olszewski, }\end{array}$ & Poland \\
\hline 5 & 1886 & $54^{0} \mathrm{~K}$ & $\begin{array}{c}\text { Oxygen solidified } \\
\text { James Dewar, } \\
\text { Robert Lennox \& } \\
\text { James Heath, }\end{array}$ & England \\
\hline 6 & 1898 & $21^{0} \mathrm{~K}$ & Hydrogen liquefied & $\begin{array}{c}\text { James Dewar, } \\
\text { Robert Lennox \& } \\
\text { James Heath, }\end{array}$ & England \\
\hline 7 & 1899 & $14^{0} \mathrm{~K}$ & Hydrogen solidified & $\begin{array}{c}\text { James Dewar, } \\
\text { Robert Lennox }\end{array}$ & England \\
\hline
\end{tabular}


International Advanced Research Journal in Science, Engineering and Technology

Vol. 7, Issue 10, October 2020

DOI 10.17148/IARJSET.2020.71006

\begin{tabular}{|c|c|c|c|c|c|}
\hline 8 & 1908 & $1^{0} \mathrm{~K}$ & $\begin{array}{l}\text { Evaporation of liquid } \\
\text { helium }\end{array}$ & $\begin{array}{l}\text { Heike } \underline{\text { Kamerlingh }} \\
\underline{\text { Onnes, }},\end{array}$ & Netherlands \\
\hline 9 & 1926 & $0.95^{0} \mathrm{~K}$ & $\begin{array}{c}\text { Helium solidified } \\
\text { under } 26 \text { atm pressure }\end{array}$ & Willem Keesom, & Netherlands \\
\hline 10 & 1933 & $0.27^{0} \mathrm{~K}$ & $\begin{array}{c}\text { Adiabatic } \\
\text { demagnetization of } \\
\text { paramagnetic salts } \\
\text { Wander de Haas, } \\
\text { Netherlands } \\
\end{array}$ & Wander de Haas, & Netherlands \\
\hline 11 & 1956 & $\left(16 \times 110^{-4}\right)^{0} \mathrm{~K}$ & $\begin{array}{l}\text { Adiabatic nuclear } \\
\text { demagnetization }\end{array}$ & $\begin{array}{c}\text { Nicholas } \underline{\text { Kurti \& Fr }} \\
\text { ancis } \underline{\text { Simon, }}\end{array}$ & England \\
\hline 12 & 1993 & $\left(280 \times 10^{-12}\right)^{0} \mathrm{~K}$ & $\begin{array}{c}\text { Adiabatic Nuclear } \\
\text { Demagnetization of } \\
\text { Rhodium }\end{array}$ & & \\
\hline 13 & 1995 & $\begin{array}{c}\text { Order of Nano } \\
\text { Kelvin }\end{array}$ & $\begin{array}{c}\text { Adiabatic Nuclear } \\
\text { Demagnetization of } \\
\text { Rhodium }\end{array}$ & $\begin{array}{c}\text { Carl Wieman, } \\
\text { Wolgang Ketterle } \\
\text { and Allin Cornell } \\
\end{array}$ & United States \\
\hline 14 & 1999 & $\left(250 \times 10^{-12}\right)^{0} \mathrm{~K}$ & $\begin{array}{l}\text { Adiabatic Nuclear } \\
\text { Demagnetization }\end{array}$ & & $\begin{array}{c}\text { Helsinki } \\
\text { University of } \\
\text { Technology, } \\
\text { Finland }\end{array}$ \\
\hline 15 & 2000 & $\left(100 \times 10^{-12}\right)^{0} \mathrm{~K}$ & $\begin{array}{l}\text { Adiabatic Nuclear } \\
\text { Demagnetization }\end{array}$ & & $\begin{array}{c}\text { Helsinki } \\
\text { University of } \\
\text { Technology, } \\
\text { Finland }\end{array}$ \\
\hline 16 & 2015 & $\left(50 \times 10^{-12}\right)^{0} \mathrm{~K}$ & Matter Wave Lensing & & $\begin{array}{c}\text { Stanford } \\
\text { University, } \\
\text { Californis,US } \\
\end{array}$ \\
\hline
\end{tabular}

They all go in pairs and by the Pauli Exclusion principle, the spins are anti-parallel and hence the resultant spin is zero. Thus the photon of a helium atom qualifies to be a Boson which will permit us to apply Bose-Einstein Statistics.

Helium becomes a liquid at $4 \mathrm{~K}$ and it experiences a peculiar change of state at a temperature of $2.19 \mathrm{~K}$ and at atmospheric pressure. The behavior at gaseous state and at liquid state are two different things. But, however, liquid helium is a monatomic liquid and scientist S N Bose (1894-1974) (Fig.26) applied the Bose-Einstein Statistics to a helium gas with the values for liquid helium and obtained the transition temperature or the Bose temperature as follows:

Let $\mathrm{N}$ be the total number of particles in the system and occupying a gas volume, $\mathrm{V}$ and given by

$$
\mathrm{N}=\frac{2}{\sqrt{\pi}} \cdot\left(\frac{2 \pi \mathrm{m} \mathrm{kT}}{h^{2}}\right)^{\frac{3}{2}} \mathrm{~V} \int_{0}^{\infty}\left(\frac{\sqrt{\mathrm{x}}}{\mathrm{e}^{\mathrm{x}}-1}\right) \mathrm{dx} \ldots \ldots \ldots \ldots \ldots
$$




\section{International Advanced Research Journal in Science, Engineering and Technology \\ Vol. 7, Issue 10, October 2020}

DOI 10.17148/IARJSET.2020.71006

where $\mathrm{T}$ is the absolute thermodynamic temperature, $\mathrm{k}$ the Boltzmann constant the value of which is $1.38 \times 10^{-23} \frac{\mathrm{J}}{\mathrm{K}}, \mathrm{m}$ the mass of the particle which here is the mass of one helium atom and is equal to $6.65 \times 10^{-27} \mathrm{~kg}$, h the Planck's constant equal to $6.63 \times 10^{-34}$ Js and $\mathrm{N}$ can be the Avagadro's number equal to $6.02 \times 10^{23}$.

The integral on the right of equation (17) can be solved as [11]

$$
\int_{0}^{\infty}\left(\frac{\sqrt{\mathrm{x}}}{\mathrm{e}^{\mathrm{x}}-1}\right) \mathrm{dx}=\frac{\sqrt{ } \pi}{2} \sum_{n=1}^{\infty} \frac{1}{n^{\frac{3}{2}}}=\frac{\sqrt{ } \pi}{2} \times 2.612=2.31 \ldots \ldots
$$

Thus the equation (17) may be re-written as

$$
\begin{aligned}
& \mathrm{N}=\frac{2}{\sqrt{\pi}} \cdot\left(\frac{2 \pi \mathrm{mkT}}{h^{2}}\right)^{\frac{3}{2}} \mathrm{~V}(2.31) \\
& \therefore\left(\frac{2 \pi \mathrm{mkT}}{\mathrm{h}^{2}}\right)^{\frac{3}{2}}=\left(\frac{\mathrm{N}}{\mathrm{V}}\right)\left(\frac{1}{2.31}\right)\left(\frac{\sqrt{\pi}}{2}\right)=\left(\frac{\mathrm{N}}{\mathrm{V}}\right)\left(\frac{\sqrt{\pi}}{4.62}\right) \\
& \therefore\left(\frac{2 \pi \mathrm{m} \mathrm{kT}}{\mathrm{h}^{2}}\right)=\left[\left(\frac{\mathrm{N}}{\mathrm{V}}\right)\left(\frac{\sqrt{\pi}}{4.62}\right)\right]^{\frac{2}{3}} \\
& \text { or } \quad T=\left(\frac{h^{2}}{2 \pi m k}\right)\left[\left(\frac{N}{V}\right)\left(\frac{\sqrt{\pi}}{4.62}\right)\right]^{\frac{2}{3}}
\end{aligned}
$$

Now, consider 1 liter of helium so that $\mathrm{V}=1$ liter $=0.001=10^{-3}$ cubic meter and substituting other values, we get

$$
\begin{aligned}
\mathrm{T} & =\left[\frac{\left(6.63 \times 10^{-34}\right)^{2}}{(2 \times 3.142) \times\left(6.65 \times 10^{-27}\right) \times\left(1.38 \times 10^{-23}\right)}\right]\left[\left(\frac{1.773}{4.62}\right)\left(\frac{6.02 \times 10^{23}}{10^{-3}}\right)\right]^{\frac{2}{3}} \\
& =\frac{\left(44 \times 10^{-68}\right)}{\left(57.67 \times 10^{-50}\right)}\left[\left(\frac{1.773}{4.62}\right)\left(\frac{6.02 \times 10^{23}}{10^{-3}}\right)\right]^{\frac{2}{3}} \\
& =\left(0.763 \times 10^{-18}\right)\left[0.384 \times 6.02 \times 10^{26}\right]^{\frac{2}{3}} \\
& =\left(0.763 \times 10^{-18}\right)\left(2.312 \times 10^{26}\right)^{\frac{2}{3}} \\
& =\left(0.763 \times 10^{-18}\right)\left(2.157 \times 10^{18}\right) \\
& =(0.763 \times 2.157)=1.646 \\
\therefore \mathrm{T} & =1.646^{0} \mathrm{~K}
\end{aligned}
$$

This matches with the temperature, $1.714^{0} \mathbf{K}$ corresponding to vapor pressure of $1 \mathrm{~cm}$ of mercury [21a,]

5.3. The Discovery of the Bose-Einstein Condensate: We are now going to keep our final Step. With enough mathematical background, with a temperature as low as $0.844 \mathrm{~K}$ already reached by Onnes in 1911 and with modern methods of magnetic cooling and laser cooling already in existence, the year 1995 became a golden year of the $20^{\text {th }}$ century by actually arriving at the Bose-Einstein Condensate, the $5^{\text {th }}$ state of matter. In 1995, the American physicists, Eric Allin Cornel (b.1961-) (Fig.36) and Carl Wieman (b.1951-) (Fig.34) of the university of Colarado, US cooled gas of Rubidium-87 atoms to about 
International Advanced Research Journal in Science, Engineering and Technology

Vol. 7, Issue 10, October 2020

DOI 10.17148/IARJSET.2020.71006

one-sixth of a millionth of a Kelvin. A German physicist, Wolfgang Ketterle (b.1957-) (Fig.35) working at Massachusetts Institute of Technology (MIT), US also arrived at the same result. All the three shared the 2001 Nobel Prize in Physics.

I would like to give some excerpts from the Nobel Lecture by Wolfgang Ketterle one of the winners of the Nobel Prize. The experimental arrangement is shown in Fig.37.. A toms are trapped by a strong magnetic field generated by two coils In the center the magnetic field vanishes which allows the atoms to spin flip and escape. Therefore the atoms are kept away from the center of the trap by a strong ( $35 \mathrm{~W})$ argon-ion laser beam ("Optical Plug") which exerts a repulsive force on the atoms. Evaporative cooling is controlled by radiofrequency radiation from an antenna. The radiofrequency selectively flips the spans of the most energetic atoms. The remaining atoms re-thermalize (at lower temperature) by collisions among themselves. Evaporative cooling is forced by lowering the radiofrequency.

The state of affairs taking place from the point of view of Quantum Mechanics is shown in Fig.38 At high temperature $\mathrm{T}$ trapped atoms behave as billiard balls with thermal velocity $\mathrm{v}$ and density $\mathbf{d}^{-\mathbf{3}}$ as shown in Fig (a). As the temperature is lowered, the De Broglie wavelength $\boldsymbol{\lambda}_{\mathbf{d B}}$ is proportional to $\mathbf{T}^{-\frac{\mathbf{1}}{2}}$ wave packets. As shown in Fig (b). When the temperature $\mathrm{T}=\mathbf{T}_{\mathbf{c}}$ the critical temperature, $\mathrm{d}=\boldsymbol{\lambda}_{\mathbf{d B}}$, the matter waves overlap as shown $\mathrm{i}(\mathrm{c})$. When $\mathrm{T}=0$, the giant matter wave appears with pure Bose condensate as shown in (d).

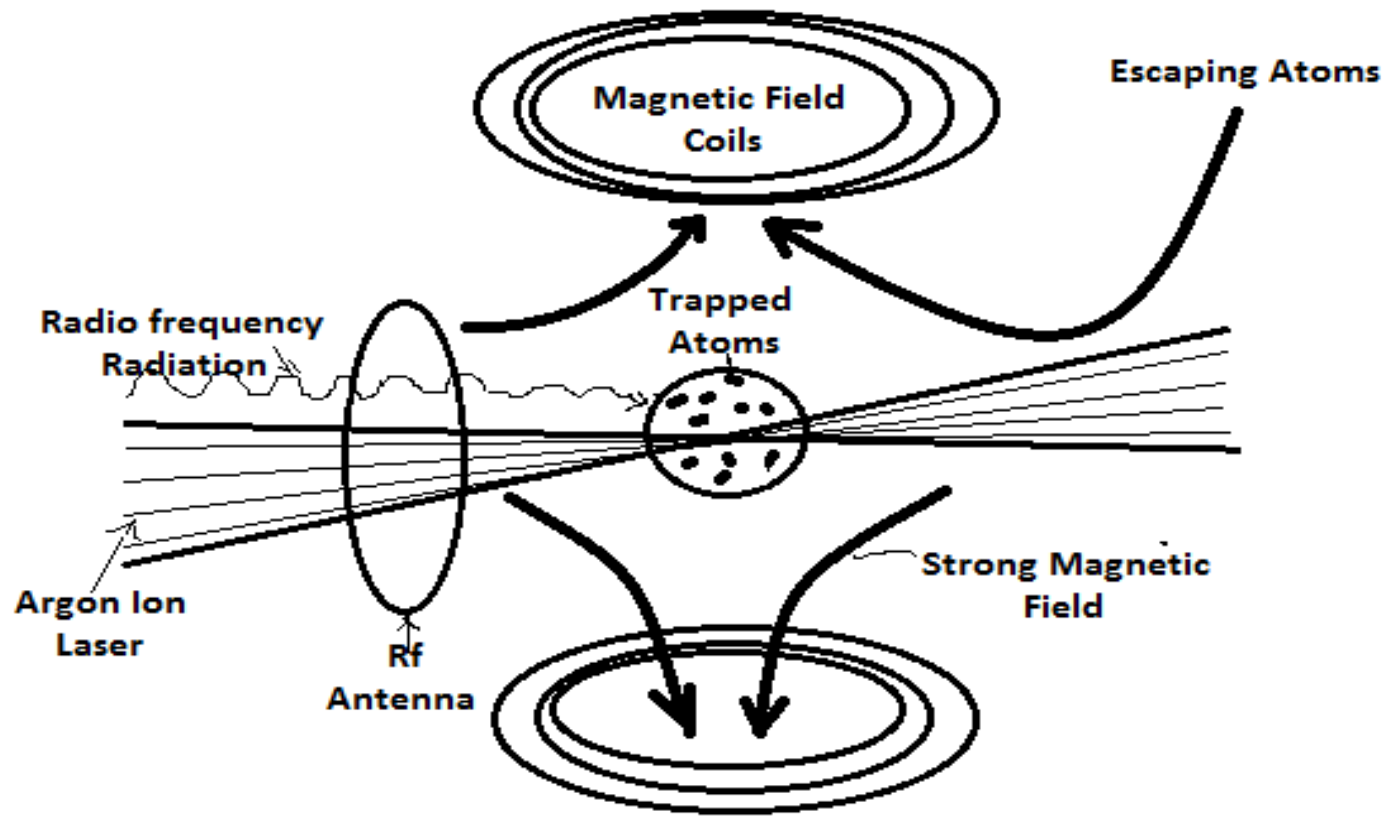

Fig..37 Pictorial illustration of the cooling process

The scientists had a glimpse of the computer-generated photographs of the condensate at temperatures as low as 50 Nano Kelvin and the same is shown in Fig.38. The first diagram corresponds to the velocity distribution data when the condensate just begins to form, the second one is just after appearance and the third one the final condensate after sufficient evaporation. After the discovery, Cornel said: It is altogether a different kind of matter so cold that one can achieve only in a laboratory and not even in 
International Advanced Research Journal in Science, Engineering and Technology

Vol. 7, Issue 10, October 2020

DOI 10.17148/IARJSET.2020.71006

interstellar space where the temperature is slightly higher due the back ground radiation left out by the Big Bang.

The MIT researchers could attain temperatures as low as 0.45 Nano Kelvin in 2003. A view of the laboratory at MIT, US where the outstanding discovery was done, is shown in Fig.40

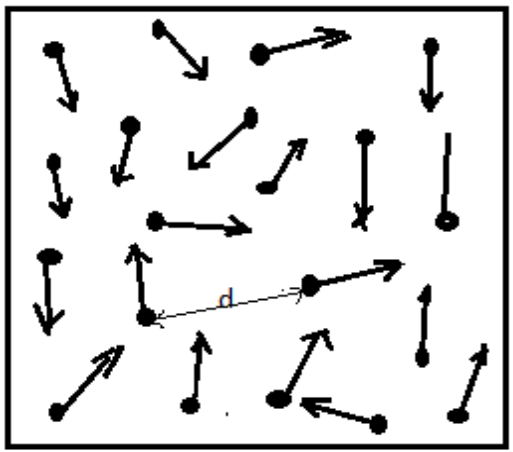

(a)

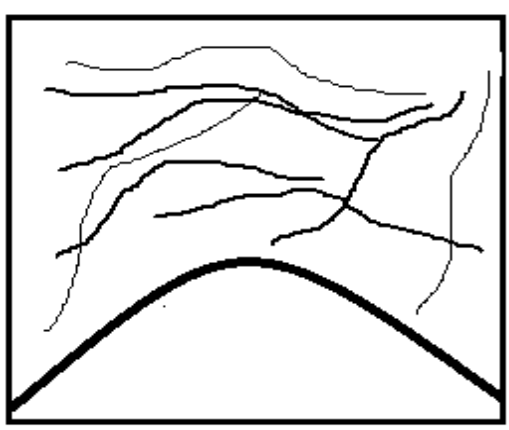

(c)

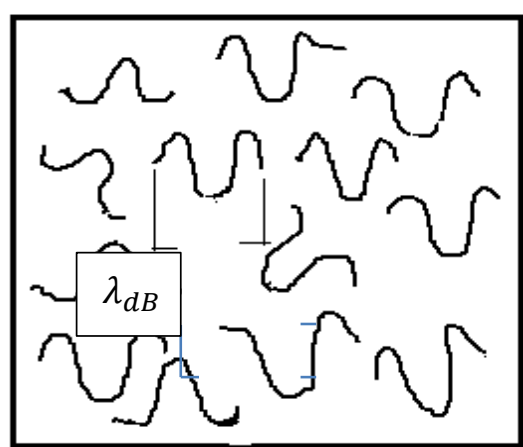

(b)

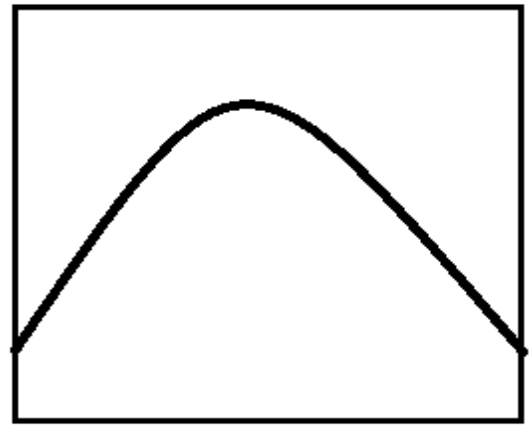

(d)

Fig.38 Illustration of the behavior of trapped atoms

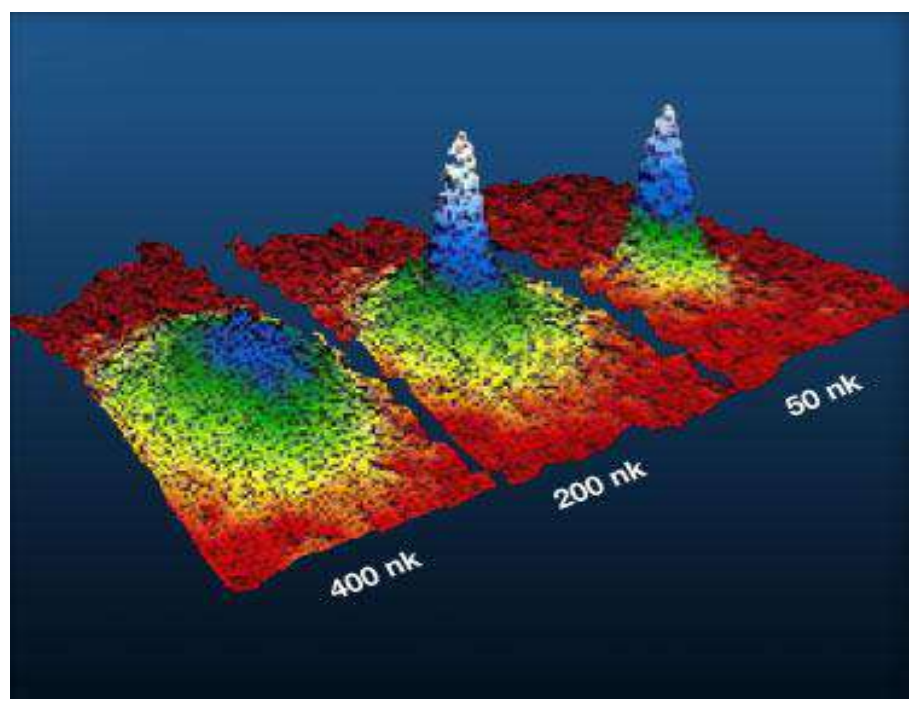

Fig 39 The gradual formation of the condensate at various extremely low temperatures 


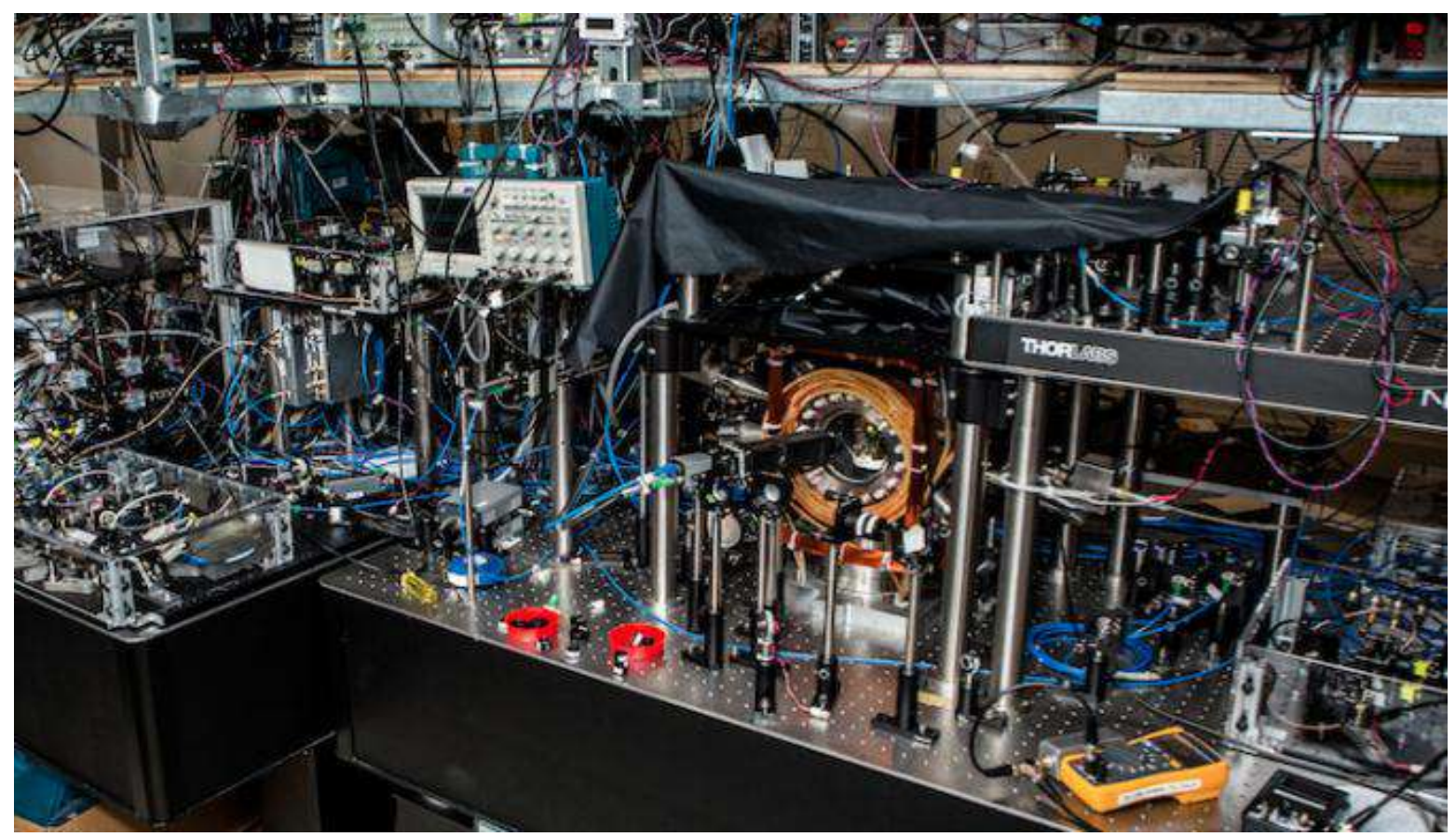

Fig.40 The Laboratory for cooling atoms at MIT, US [14, Fig.38, p.69]

\section{NERNST HEAT THEOREM AND THE THIRD LAW OF THERMODYNAMICS (ABSOLUTE ZERO) (THE IMPOSSIBILITY IV)}

6.0. The Preample: From Physics we now enter into Chemistry without dealing with any of its subject matter. Once upon a time during the time of British Chemist, John Dalton (1766-1844) both the subjects Physics and Chemistry were included as Science and Dalton felt that the two must have separate entity and existence and hence Physics and Chemistry remained as independent subjects. The concept of Absolute Zero is both in Physics and Chemistry and Physics has more and first right to get it included in Physics, I make this statement not just because I am a Physicist but the pioneers right from the $17^{\text {th }}$ century who worked on Absolute Zero were all Physicists such as Lord Kelvin and many others. In a lighter vein I would like to say that the tussle between physicists and chemists is age-old and some of them are even at loggerheads. There is no wonder that the discovery of the Bose-Einstein Condensate has been done exclusively by 3 American physicists who were jointly awarded the 2001 Nobel Prize.

It is of great interest and important to highlight the contribution of a renowned German chemist Walther Nernst (1864-1941) (Fig. ) in the topic of absolute zero and Entropy.

From the point of view of thermodynamics, the infinitesimal change in Gibbs free energy $\mathrm{G}$ is equal to the infinitesimal change in enthalpy $\mathrm{H}$ of the system as explained below:

The Gibbs-Helmholtz equation is given by

$$
\Delta \mathrm{G}=\Delta \mathrm{H}+\mathrm{T}\left(\frac{\partial(\Delta \mathrm{G})}{\partial \mathrm{T}}\right) .
$$




\section{International Advanced Research Journal in Science, Engineering and Technology \\ Vol. 7, Issue 10, October 2020}

DOI 10.17148/IARJSET.2020.71006

The bracketed quantity in the second term on the right of equation (19) is equal to negative of $\Delta \mathrm{S}$. That is, $\left(\frac{\partial(\Delta \mathrm{G})}{\partial \mathrm{T}}\right)=-\Delta \mathrm{S}$. Thus, equation (19) becomes

$$
\Delta \mathrm{G}=\Delta \mathrm{H}-\mathrm{T} \Delta \mathrm{S}
$$

$$
\text { When } \mathrm{T} \rightarrow 0, \Delta \mathrm{G}=\Delta \mathrm{H}
$$

Nernst also noted that as $\mathrm{T} \rightarrow 0$, the quantity, $\frac{\partial(\Delta \mathrm{G})}{\partial \mathrm{T}}$ gradually approaches zero .

Equation, (20) justifies the theorem. Nernst further said that:

"It is impossible by any procedure no matter how idealized to reduce the temperature of any system to the absolute zero of temperature in a finite number of finite operations".
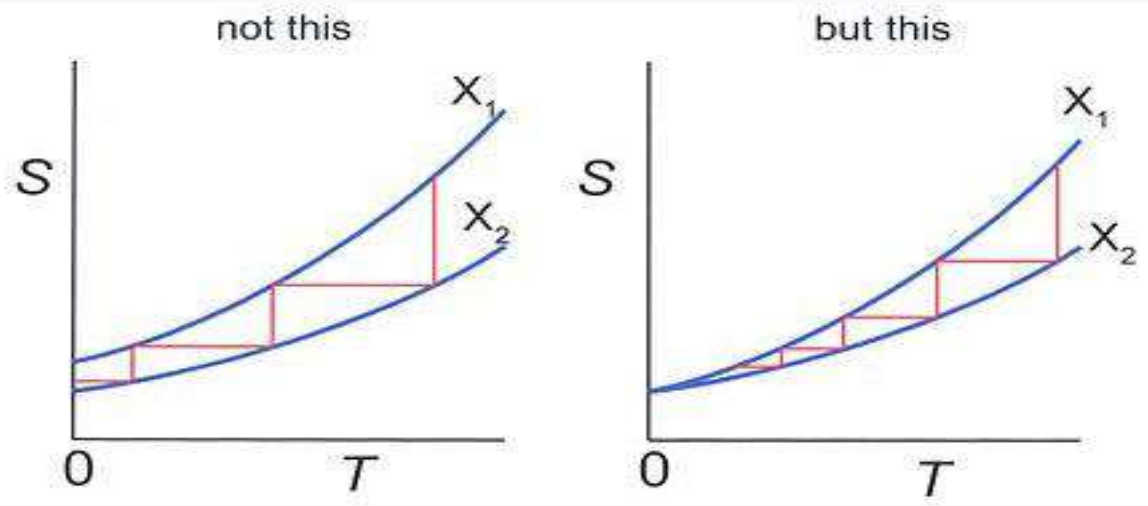

Fig.41 Illustration of the unattainability of Absolute Zero [ ]

The reason that $\mathrm{T}=0$ cannot be reached according to the third law is explained as follows: Suppose that the temperature of a substance can be reduced in an isentropic process by changing the parameter $\mathrm{X}$ from $\mathrm{X}_{2}$ to $\mathrm{X}_{1}$. One can think of a multistage nuclear demagnetization setup where a magnetic field is switched on and off in a controlled way. If there were an entropy difference at absolute zero, $\mathrm{T}=0$ could be reached in a finite number of steps. However, at $\mathrm{T}=0$ there is no entropy difference so an infinite number of steps would be needed. The process is illustrated in Fig.41. The graph on the left indicates the attainment of Absolute Zero in a finite number of steps if $S\left(0, X_{1}\right) \neq S\left(0, X_{2}\right)$. The graph on the right indicates the requirement of infinite number of steps since $S\left(0, X_{1}\right)=S\left(0, X_{2}\right)$.

I am glad to mention that the 1920 Chemistry Nobel Prize was awarded to Walther Nernst and the other chemist of fame in this connection regarding Specific Heats was Peter Debye (1884-1966) to win the 1936 Nobel Prize in Chemistry.

6.1 Third Law of Thermodynamics: A Live Science Contributor, Jim Lucas [5], poses a question, What is the Third Law of Thermodynamics? The Third Law of Thermodynamics is concerned with the 


\section{International Advanced Research Journal in Science, Engineering and Technology}

Vol. 7, Issue 10, October 2020

DOI 10.17148/IARJSET.2020.71006

limiting behavior of systems as the temperature approaches absolute zero. Most thermodynamics calculations use only entropy differences, so the zero point of the entropy scale is often not important. However, we discuss the Third Law for purposes of completeness because it describes the condition of zero entropy.

The Third Law states, "The entropy of a perfect crystal is zero when the temperature of the crystal is equal to absolute zero $\left(0^{0} \mathrm{~K}\right)$." According to Purdue University, "The crystal must be perfect, or else there will be some inherent disorder. It also must be at $0 \mathrm{~K}$; otherwise there will be thermal motion within the crystal, which leads to disorder."

Siabal Mitra, [22] a professor of physics at Missouri State University, provides another implication of this law.. "One version of the Third Law states that it would require an infinite number of steps to reach absolute zero, which means you will never get there. If you could get to absolute zero, it would violate the Second Law, because if you had a heat sink at absolute zero, then you could build a machine that was 100 percent efficient."

In theory it would be possible to grow a perfect crystal in which all of the lattice spaces are occupied by identical atoms. However, it is generally believed that it is impossible to achieve a temperature of absolute zero (although scientists have come quite close - See a comic illustration in the Conclusion). Therefore, all matter contains at least some entropy owing to the presence of some heat energy. From the point of view of thermodynamics, the infinitesimal change in Gibbs free energy $G$ is equal to the infinitesimal change in enthalpy $\mathrm{H}$ of the system as explained below:

Max-Planck-Gesellschaft [13]: says: "A temperature below absolute zero" Atoms at negative absolute temperature are the hottest systems in the world

On the absolute temperature scale, which is used by physicists and is also called the Kelvin scale, it is not possible to go below zero - at least not in the sense of getting colder than zero kelvin. According to the physical meaning of temperature, the temperature of a gas is determined by the chaotic movement of its particles - the colder the gas, the slower the particles. At zero kelvin (minus 273 degrees Celsius) the particles stop moving and all disorder disappears. Thus, nothing can be colder than absolute zero on the Kelvin scale. Physicists have now created an atomic gas in the laboratory that nonetheless has negative Kelvin values. These negative absolute temperatures have several apparently absurd consequences: although the atoms in the gas attract each other and give rise to a negative pressure, the gas does not collapse - a behavior that is also postulated for dark energy in cosmology.

\subsection{Negative Temperatures:}

Casas Vazquez [3] Certain semi-isolated systems (for example a system of non-interacting spins in a magnetic field) can achieve "negative" temperatures. They, however, are not actually colder than absolute zero. They can be thought of as "hotter than $\mathrm{T}=\infty$ ", as energy will flow from a negative temperature system to any other system with positive temperature upon contact.

States with negative temperature are hotter than states with positive temperature, as they tend to give energy to the latter when put in mutual thermal contact. Thus, the scale from cold to hot runs in fact 
as $+0 \mathrm{~K}, \ldots,+273 \mathrm{~K}, \ldots,+\infty \mathrm{K},-\infty \mathrm{K}, \ldots,-273 \mathrm{~K},-0 \mathrm{~K}$; thus, a natural choice of a temperature scale would be provided by $-1 / \mathrm{T}$, which runs according to this ordering. In fact, the conditions for the existence of states at negative temperatures are very restrictive, in such a way that in practice they are rarely met except in some mutually interacting nuclear spin systems-

6.3 Corollary: Note that the exact definition of entropy is

Entropy $=($ Boltzmann's constant $\mathrm{k}) \mathrm{x}$ logarithm of number of possible states. That is, $\mathrm{S}=\mathrm{k}_{\mathrm{B}} \log \mathrm{W}$

This equation, which relates the microscopic details, or microstates, of the system (via W) to its macroscopic state (via the entropy $\boldsymbol{S}$ ), is the key idea of statistical mechanics.

6.3.1Absolute zero is the coldest theoretical temperature, at which the thermal motion of atoms and molecules reaches its minimum. This is a state at which the enthalpy and entropy of a cooled ideal gas reaches its minimum value, taken as 0 .

Mathematically:

$\lim _{\mathrm{T} \rightarrow 0} \mathrm{~S}=0$ where

$\mathrm{S}=$ entropy $(\mathrm{J} / \mathrm{K})$

$\mathrm{T}=$ absolute temperature $(\mathrm{K})$

Classically, this would be a state of motionlessness, but quantum uncertainty dictates that the particles still possess a finite zero-point energy.

\section{CONCLUSION}

If one believes in the existence of 'soul', after death, as mentioned in the Bhagavad Gita*, the Zero Point Energy (ZPE) corresponds to the soul of any living being, man, animal or plants after they perish. The matter appears to have perished, but the energy is not. ZPE also known as the ground energy is the ultimate surviving energy of Quantum Mechanics left out by the Big Bang and that is what is holding the Universe together. Astronomers and astrophysicists need not even think of a Big Crunch which will never happen as the ground energy is eternal like the soul of any living organism.

When I visited the Yosemite Water Falls in the State of California, US and the second one in fame to the Niagara Water Falls, my sight struck at the huge forest of trees in the neighboring forest. A forest guard explained to visitors that some of the trees are of height some 300 feet or thereabout and have tremendous growth. A car can move through a small road made through the fatty trunk of a tree. The forest fires are sometimes natural, he says for the growth of a new generation. Even an unburnt root springs out a new tree. As a physicist, I thought for a moment. Here is the presence of Zero Point Energy and the new growth maintains to protect climate change. Even biological systems are governed by laws of Physics. Here, I would like to repeat a philosophical statement I made in one of my earlier papers titled "An Arm-Chair Philosophy from a Physicist". The statement is, "Physics is more lively than any living Biological Science".

I have brought this lengthy paper to an end. This is a real Paper on Foundations and Frontiers of Physics specially pertaining to the Zero Point Energy. The Zero Point Energy, $\frac{1}{2} \mathrm{~h} v$ just contains three quantities, $\frac{1}{2}$, h and $v$ and appears to be very simple. But, when it comes to interpretation and explanation, covers astrophysics, astronomy and even cosmology pertaining to the entire Universe. I call the ZPE, $\frac{1}{2}$ $\mathrm{h} v$, a Quantum Magician with several magic wands. It is peculiar in the sense that the photon energy, 
DOI 10.17148/IARJSET.2020.71006

$\mathrm{h} v$ of Einstein is split into two which temperamentally Einstein does not like. If you ignore the frequency, $v$, it will amount to splitting the Planck's constant and that will damage the entire Physics. The only reasonable alternative is to split the frequency, $v$ and that has been actually done satisfying both Planck and Einstein. I have just mentioned about this somewhere in the text of this Paper also.

Zero-point energy, also known as ground state energy, could be the greatest gift the quantum world can ever give us. It's a byproduct of the fact that subatomic particles don't really behave like single particles, but like waves constantly flitting between different energy states. This means even the seemingly empty vacuum of space is actually a roiling sea of virtual particles fluctuating in and out of existence, and all those fluctuations require energy.

If there's as much energy in those fluctuations as some - though definitely not all — physicists believe, and if we could ever learn how to tap into this phenomenon, we would gain access to an unparalleled source of energy reports Neel Patel in today's Inverse. Zero-point energy could power the planet with the strength of multiple suns, making it easy for us to solve Earth's energy problems forever or to travel beyond the solar system and take our place among the stars.

As human beings have a Nature controlled by Almighty, Physics, as a vast subject with its own laws and rules, the entry of ZPE has really demystified the unknown and unclear mysteries of Physics. Hats Off !!! to Max Planck for his second derivation of the Law of Thermal Radiation.

Readers are requested to go through the following philosophy of Albert Einstein and Nikola Tesla:

"Albert Einstein and Nikola Tesla suggested that we are surrounded by a 'sea of energy', which they described as invisible, boundless, and in perfect order...Everything is made of energy: molecules, pathogens, prescription medicines, and even emotions. Each cell pulses electrically, and the body itself emanates electromagnetic fields. The human body is a complex energetic system, composed of hundreds of energetic subsystems. Disease is caused by energetic imbalances; therefore, health can be restored or established by balancing one's energies."? (The Subtle Body: An Encyclopedia to Your Energetic Anatomy)

One may try however hard, but cannot attain Absolute Vacuum and Absolute Zero, Fig. 42
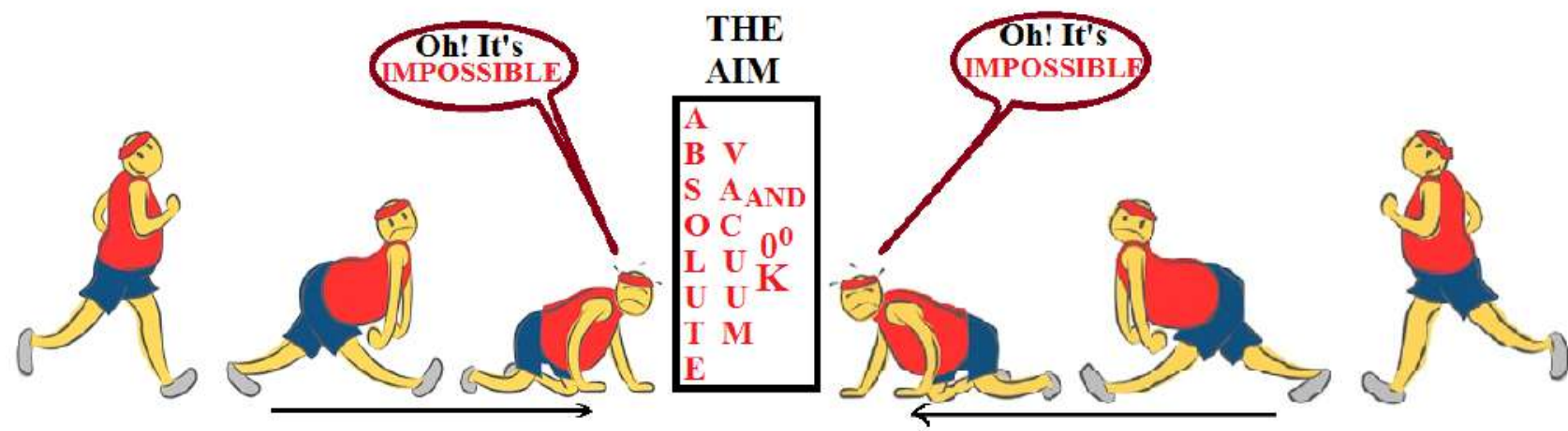

A Large Number of Physicists and Chemists running towards Absolute Vacuum and Absolute Zero and getting tired and fail to reach there

Fig.42 Illustrative diagram depicting failure to attain Absolute Vacuum and Absolute Zero 


\section{International Advanced Research Journal in Science, Engineering and Technology}

Vol. 7, Issue 10, October 2020

DOI 10.17148/IARJSET.2020.71006

Finally from the author: ".Hands Off !!! to Max Planck for his second derivation of the Law of Thermal Radiation.

\section{REFERENCES}

[1]. Aditya Saripally and Yashvardhan Srivatsava: "Study of Growth and Characteization of Metallic Films by Physical Vaporization”, Ch.7 (VHV), Fig.9, p.20, BITS Pilani, Rajasthan, India, December 2013.

[2]. Britannica: "Otto Von Guericke, Prussian physicist, engineer and philosopher" revised and updated by Richard Pallardy.

[3]. J Casas Vazquez and D Joul, 21 Department de F'isica, Universitat Autonoma de Barcelona, 08193 Bellaterra, Catalonia, Spain 2 Institut d' Estudis Catalans, Carme, 47, 08001 Barcelona, Catalonia, Spain, "Temperature in non- equilibrium states: A Review of Open Problems and current proposals; p.1957-58, 14 Oct.2003

[4]. Giuliano Franchetta; GSI Darmstadt, Vacuum I D-64291, Darmstadt, Germany; Vacuum Densities and Classification of vacuum

[5]. Jim Lucas, A Live Science Contributor; What is the Third Law of Thermodynmics? 22 May 2015.

[6]. John A Maken: Laser Physicist, St. Mary's College of California, US, 4 March 2015.

[7]. John Baez's Stuff, A Mathe matical Physicist, University of California, Riverside and also at Center for Quantum Technologies, Singapore, 10 June 2011.

[8]. John Gribbin: Q is for Quantum, An Encyclopedia of Particle Physics, A Touchstone Book, Pub. By Simon and Schuster, New York, Ed. 1998, p.69-70.

[9]. John Gribbin: Q is for Quantum, An Encyclopedia of Particle Physics, A Touchstone Book, Pub. By Simon and Schuster, New York, Ed. 1998, p.418

[10]. Karve \& Shah: A First Course in Elementary Physics, Pub. S Chand \& Co., Ed. 1969, Ch.12, p.179.

[11]. Kompaneyets A.S.: Theoretical Physics, Foreign Language Publishing House,, Moscow, 1961, Bose Condensation, Part IV, Sec.43, p.475-476. Also Appendix p.587.

[12]. Lynn Cominsky: An American Astrophysicist and Educator who is currently the Chair of Astronomy and Physics at Sonoma State University in Rohnert Park, California, as well as the Project Director for the NASA Education and Public Outreach Group, 19 July 2007.

[13]. Max Planck-Gesellschaft: A Temperature below Absolute Zero, "Atoms at negative absolute temperature are the hottest systems in the world", 4 January 2013.

[14]. Nair V.C.A: "The Four Steps to the Fifth State of Matter", International Advanced Research Journal in Science, Engineering and Technology, Vol.5, Issue-3, March 2018, p.65-71.

[15]. NASA: The Wilkinson Microwave Anisotropy Probe (WMAP), a NASA Explorer, Universe 101 reports informationupdated as on $24 \mathrm{Jan} .2014$.

[16]. Niels Marquardt: "Introduction to the Principles of Vacuum Physics", Institute for Accelerator Physics and Synchroton Radiation, University of Dortmund, 44221 Dortmund, Germany.p.1-4

[17]. Peter W Milonni:"Compendium of Quantum Physics", p.864-866.

[18]. Reynal and Hitchcock: "Pascal the Life of Genius" New York, Ed. 1936, p.49.

[19]. Richard Fitzpatrick: of University of Texas, Austin, US. 2016-01-25

[20]. F.K. Richtmyer, E.H. Kennard and John N. Cooper, MacGraHill Book Co.Ed.1969,Eqn (5.19), p.131.

[21]. Roberts J,K,: Heat \& Thermodynamics, Blackie \& Son Ltd., $3^{\text {rd }}$ Ed. Reprint 1943, Ch. XXI, Sec.8, p.432.

[21a]. Roberts J,K,: Heat \& Thermodynamics, Blackie \& Son Ltd., $3^{\text {rd }}$ Ed. Reprint 1943, Ch.V,sec.10, Table III.

[22]. Siabal Mitra:Aprofessor of Physics at Missouri State University, US.

[23]. Scientific American: 22 June 1998

[24]. Stephen Battersby: An astrophysicist, a Ph.D from Imperial College, London: A freelance science journalist; 20 November 2008.

[25]. From a contemporary physicist (assumed to be Sir James Jeans) from "The Mysterious Universe”, Lloyd William Taylor: "Physics, The Pioneer Science, Vol. I and II, Dover Publications, New York, Ed.1959. A Millan, New York, 1930, p.1-163. Reproduced by Lloyd W. Taylor p.768 (end of Ch.50) 


\section{International Advanced Research Journal in Science, Engineering and Technology}

Vol. 7, Issue 10, October 2020

DOI 10.17148/IARJSET.2020.71006

[26]. Lloyd William Taylor "Physics, The Pioneer Science, Vol. I and II, Dover Publications, New York, Ed.1959. Fig.78, p.104

[27]. Lloyd William Taylor "Physics, The Pioneer Science, Vol.I \& II, Dover Publications, New York, Ed.1959. Geissler's Vacuum Pump, Fig.503 (p.770); p.769-770

[28]. Lloyd William Taylor: "Physics, The Pioneer Science, Vol. I and II, Dover Publications, New York, Ed.1959 Planck's Quantum Theory of Radiation, p.810

[29]. Trang T. Nguyen: "Casimir Effect and Vacuum Fluctuations" Department of Physics and Astronomy, Ohio University, US, Spring 2003, p.1-7.

[30]. Wikipedia:

\section{BIOGRAPHY}

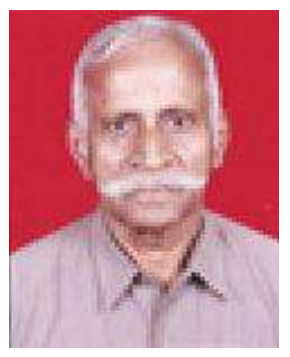

Dr.(Prof.) V.C.A. Nair* (b.15 ${ }^{\text {th }}$ Aug. 1939) is an Educational Physicist, Counselor, Research Guide and Consultant. He did his Masters in Physics from Mumbai University, India and Ph.D. from Shri. JJT University, Rajasthan also in India He is a Research Guide and distinguished alumnus of JJT University. He is also a Chancellor designated Resource Person in the area of Physics of the University. He has to his credit over 4 decades of teaching Applied Physics in eminent Polytechnics in Mumbai and having taught nearly 16,000 students since 1965. He has published a number of research papers in Physics and Geophysics in International and UGC ${ }^{\circledR}$ recognized Journals some of which can be seen in the net 'Google Search' when the name of the author or his email is clicked in that style. He has successfully guided $3 \mathrm{Ph.D}$ Scholars of Shri JJT University leading to their Ph.D Degrees. He is a Life Member of Indian Society for Technical Education which is an all India body. He had been to USA a number of times and visited eminent Universities such as Stanford, Harvard, MIT, 3 Universities of California at Berkeley, Los Angeles and also at Davis, University of Princeton at New Jersey, Roosevelt University at Chicago, University of Chicago and University of San Francisco. At present Dr. Nair is a Research Guide for Physics at Shri JJT University, Rajasthan-333001, India. He is a member of the Editorial Board of this Journal. His Ph.D. Thesis is in Geophysics and he is working on topics such as Volcanoes, Earthquakes, Tides, Clouds, Global Warming and Climate Change. - Editor

*nairvca39@gmail.com @University Grants Commission 